\title{
Razões da Intolerância na Europa Integrada*
}

\author{
Ana Paula Tostes
}

\section{INTRODUÇÃO}

$\mathrm{U}$

ma das consequências da União Europeia (UE) e sua complexa euroburocracia foi a internalização de relações entre países, anteriormente manejadas segundo dinâmicas internacionais diplomáticas. Assim, iniciativas de cooperação ou conflitos antes resolvidos no âmbito das relações exteriores dos Estados europeus são hoje negociados no Conselho de Ministros ou no Parlamento Europeu. As instituições regionais são novos atores também da política nacional dos países europeus envolvidos no processo de integração europeia. No âmbito de um processo político complexo, como é o caso europeu contemporâneo, consequências da política regional refletem na preferência do eleitor em eleições nacionais. Por conseguinte, o perfil ideológico dos partidos políticos e seu posicionamento diante de temas da política regio-

\footnotetext{
* Este artigo é um resultado parcial de uma agenda de pesquisa que segue seu curso. Desde o projeto até a versão final, este estudo foi objeto de apresentação em conferências e debates públicos: conferência da European Consortium for Political Research (ECPR), em Pisa, setembro de 2007; conferência da Midwest Political Science Association (MPSA), em Chicago, abril de 2008, e VI Encontro da Associação Brasileira de Ciência Política (ABCP), em Campinas, julho de 2008. O resultado final aqui publicado se deve também àqueles que se dispuseram a ler versões incompletas, debater os problemas e apontar críticas, incentivar o trabalho e dar sugestões. Assim, agradeço aos debatedores dessas conferências, aos pareceristas anônimos da revista $D A D O S$, que sempre tornam o resultado melhor, e, especialmente, a Carlos Pereira, não apenas as leituras e conversas mas também o apoio incondicional nesse processo.
}

DADOS - Revista de Ciências Sociais, Rio de Janeiro, Vol. 52, n²2, 2009, pp. 335 a 376. 
nal são levados em conta não apenas nas eleições europeias mas também nas eleições nacionais na Europa. A percepção de um deslocamento de instâncias negociadoras e decisórias na dinâmica política europeia produz consequências no cálculo das preferências eleitorais por partidos políticos em todos os âmbitos de competição eleitoral. Diante disso, eleições locais e nacionais também devem ser objeto de observação no que diz respeito ao sucesso de agendas partidárias claramente favoráveis ou desfavoráveis ao processo de integração política. A hipótese desenvolvida neste artigo é que a nova extrema-direita europeia se sustenta fortemente da oposição ao processo de integração e ao aprofundamento das políticas e das regras que incluem cidadãos de diversas nacionalidades europeias em uma só categoria de cidadania europeia. Sendo assim, a variação da performance dos partidos políticos que se opõem radicalmente à UE deve ser compreendida no contexto do desenvolvimento da integração regional, levando-se em consideração aspectos que influenciam o comportamento dos eleitores não apenas em virtude dos benefícios econômicos percebidos pela integração.

É de conhecimento do eleitor europeu que a atuação de seus chefes e ministros de Estados não se restringe mais à política doméstica, bem como sua autonomia para implementação de políticas não é mais absoluta, mas restringida por políticas europeias comuns e interesses regionais. Isso porque as instituições regionais europeias são novos atores também da política nacional dos países europeus envolvidos no processo de integração. Da mesma forma, os partidos políticos se tornaram atores de representação de interesses de grupos que se identificam mais ou menos com o projeto de integração e todas as suas consequências. De fato, o perfil ideológico dos partidos políticos e seu posicionamento diante de temas regionais são levados em conta não apenas nas eleições europeias mas também nas nacionais.

A integração europeia é um tema obrigatório nas agendas dos partidos políticos europeus e nas plataformas eleitorais nos pleitos de todos os níveis na região: locais, nacionais e europeu. Inúmeras pesquisas vêm investigando o posicionamento dos partidos políticos no que diz respeito à integração, mas pouca atenção tem sido dada a eventuais inter-relações entre o posicionamento dos partidos políticos em relação à integração e sua performance em eleições locais e nacionais. Agendas intolerantes e xenófobas de muitos partidos são incompatíveis com a agenda europeia regionalista. No entanto, em meio a variações não sistemáticas de preferências dos eleitores entre partidos de direita, cen- 
tro-direita, centro e centro-esquerda, vimos uma renovação da velha extrema-direita no seio do desenvolvimento da integração, que vem apresentando um tímido mas contínuo aumento de suporte por parte dos eleitores europeus.

Este artigo procura mapear o aumento dos votos em partidos de ideologia extremista de direita nos países europeus ocidentais individualmente e em toda a região. Primeiramente, o mapeamento do real crescimento de votos em partidos de extrema-direita na região ocidental em geral nos mostra um crescente, lento e seguro aumento de suporte a agendas intolerantes e incompatíveis com a integração europeia. Além disso, a análise por país permite visualizar em que países a tradição de suporte a essas agendas é mais ou menos forte. Nesse contexto, é preciso deixar clara a distinção entre os partidos da nova extrema-direita (PEDs) e aqueles identificados com a tradicional extrema-direita. Os últimos fortemente relacionados ao fascismo; os primeiros, representantes de uma nova clivagem política - fruto da "sociedade pós-industrial" (Betz, 1994; Ignazi, 2003). A literatura sobre o tema é rica em comparações de performances de partidos de extrema-direita entre países específicos, entre partidos específicos ou em eleições específicas europeias ou nacionais (Ignazi, 2003; Kitschelt, 1995; Taggart, 1998; Veugelers e Magnan, 2005; Veugelers e Chiarini, 2002). No entanto, não existe uma análise mais abrangente ou dados publicados sobre o suporte eleitoral dado em todos os PEDs de todos os países ocidentais ao longo de toda a existência daqueles partidos. Com o objetivo de suprir essa lacuna, foram reunidos para esta pesquisa dados de todos os países-membros ocidentais da União Europeia (UE15) dos últimos 28 anos $^{1}$, com um mínimo de cinco eleições parlamentares por país, e testadas variáveis econômicas, sociais e de representação na busca de uma contribuição para a reflexão sobre fatores regionais determinantes do suporte à intolerância ${ }^{2}$.

Alguns achados indicam que, ao contrário do que uma análise baseada nos programas políticos e nos discursos de líderes de extrema-direita poderia sugerir, a presença de imigrantes, o nível de violência ou o grau de desenvolvimento econômico não são os melhores indicadores para compreendermos o aumento da preferência de eleitores europeus ocidentais por partidos que defendem agendas de reformas não inclusivas, não pluralistas e eurocéticas. As sociedades que vêm suportando os PEDs se consideram mais informadas a respeito da UE, sendo assim mais conscientes das consequências da integração para a política 
doméstica. Além disso, vêm apresentando um bom desempenho econômico e nível de distribuição de renda; e os índices de violência nessas sociedades têm reduzido mais significativamente do que naquelas que não suportam PEDs.

\section{EUROCÉTICOS E EURO-OTIMISTAS}

Alguns estudiosos têm focado suas recentes pesquisas nas transformações do sistema partidário europeu e, especificamente, no posicionamento dos partidos políticos em relação ao processo de integração regional que se desenvolve há mais de meio século na Europa (Marks, Wilson e Ray, 2002; Marks et alii, 2006; Taggart, 1998). De Master e Roy (2000), entre outros, analisaram fatores culturais que influenciam o suporte à integração, bem como as mudanças de atitude diante de estrangeiros e imigrantes. No entanto, não é correto deduzir que uma maior população de imigrantes explicaria um maior suporte a agendas políticas xenófobas ou vice-versa ${ }^{3}$.

A maior resistência à integração social tem sido claramente identificada na emergência de um novo populismo de extrema-direita que começa a ganhar vigor no começo da década de 1980. Fortes opositores ao processo de integração são, atualmente, os simpatizantes da "nova extrema-direita" e regularmente votam em PEDs. A novidade do radicalismo de direita está ancorada, essencialmente, segundo Betz (1994), na transformação do capitalismo industrial no capitalismo pós-industrial. Transformações econômicas e sociais estruturais teriam gerado o aparecimento ou o recrudescimento de reivindicações identitárias e culturais. Consequentemente, o problema da identidade coletiva vem ganhando novas dimensões e contornos em debates contemporâneos sobre reivindicações e lealdades políticas.

Diferentes explicações buscam desenhar as condições e as motivações que levaram a retórica autoritária de extrema-direita a sofrer as profundas transformações que marcam as diferenças entre a tradicional extrema-direita, marcada sobretudo pelo fascismo (1945-1980), como já mencionado, e a nova extrema-direita, marcada pelo suporte a atitudes xenófobas e pela defesa de políticas anti-imigratórias desde a década de 1980 (Ignazi, 1996; 2003; Kitschelt, 1988; 1994; 1995; Mudde, 1996; 2007; Taggart, 1998; Veugelers e Chiarini, 2002; Veugelers e Magnan, 2005). Claramente, eventos como a integração europeia, bem como a globalização, concorrem para o desenvolvimento de demandas 
de políticas públicas de caráter não econômico. Foi fortalecida a onda de politização de novos temas, como imigração e identidade, ao mesmo tempo que a defesa de valores e crenças, e a preocupação com temas como cultura, soberania e segurança entraram fortemente nas agendas políticas do fim do século XX. Ignazi (1996; 2003) e Kitschelt (1995), ao apresentarem suas teorias sobre a emergência da nova extrema-direita, associaram-na à grande mudança no espectro da política em certos países europeus. Em outras palavras, os PEDs são identificados como um by-product das sociedades pós-industriais e classificados como "partidos antissistêmicos" (Kitschelt, 1995; Ignazi, 1996; 2003; Poguntke e Scarrow, 1996).

\section{PARTIDOS ANTISSISTÊMICOS}

Marks, Wilson e Ray (2002) classificaram os partidos políticos europeus contemporâneos segundo as clivagens sociais dos grupos de interesse que suportam famílias ideológicas partidárias. Além disso, os autores apontaram o posicionamento dos partidos em virtude do suporte ou da resistência à integração europeia em duas dimensões: política e econômica.

O Quadro 1 é esclarecedor quanto ao fato de que a absoluta resistência à integração europeia em relação a seus aspectos políticos e sociais é exclusiva dos PEDs. Estes são preferidos por eleitores que desacreditam cada vez mais o sistema representativo, o sistema partidário e as instituições democráticas. Curiosamente, ocorrem, no mesmo período, o alavancamento da integração política da UE (especificamente desde o Ato Único Europeu discutido e assinado na década de 1980), que se sustenta na derrubada de fronteiras políticas, econômicas e sociais entre os países-membros, e a consolidação de uma nova ideologia política crítica da representação. Esta última sustentada em estruturas representativas aceitas pelas regras constitucionais vigentes. O novo populismo é suportado por opositores do sistema representativo democrático que articulam suas estratégias, desde seu fortalecimento, como participantes do próprio sistema. Em outras palavras, esse novo populismo defende a queda de direitos pluralistas sem violência revolucionária ou golpista, mas desde dentro do processo político de construção de preferências.

\section{CRESCIMENTO DA EXTREMA-DIREITA NA REGIÃO}

Muitos estudiosos da extrema-direita realizam importantes estudos de política comparada considerando grupos de países ou comparando 


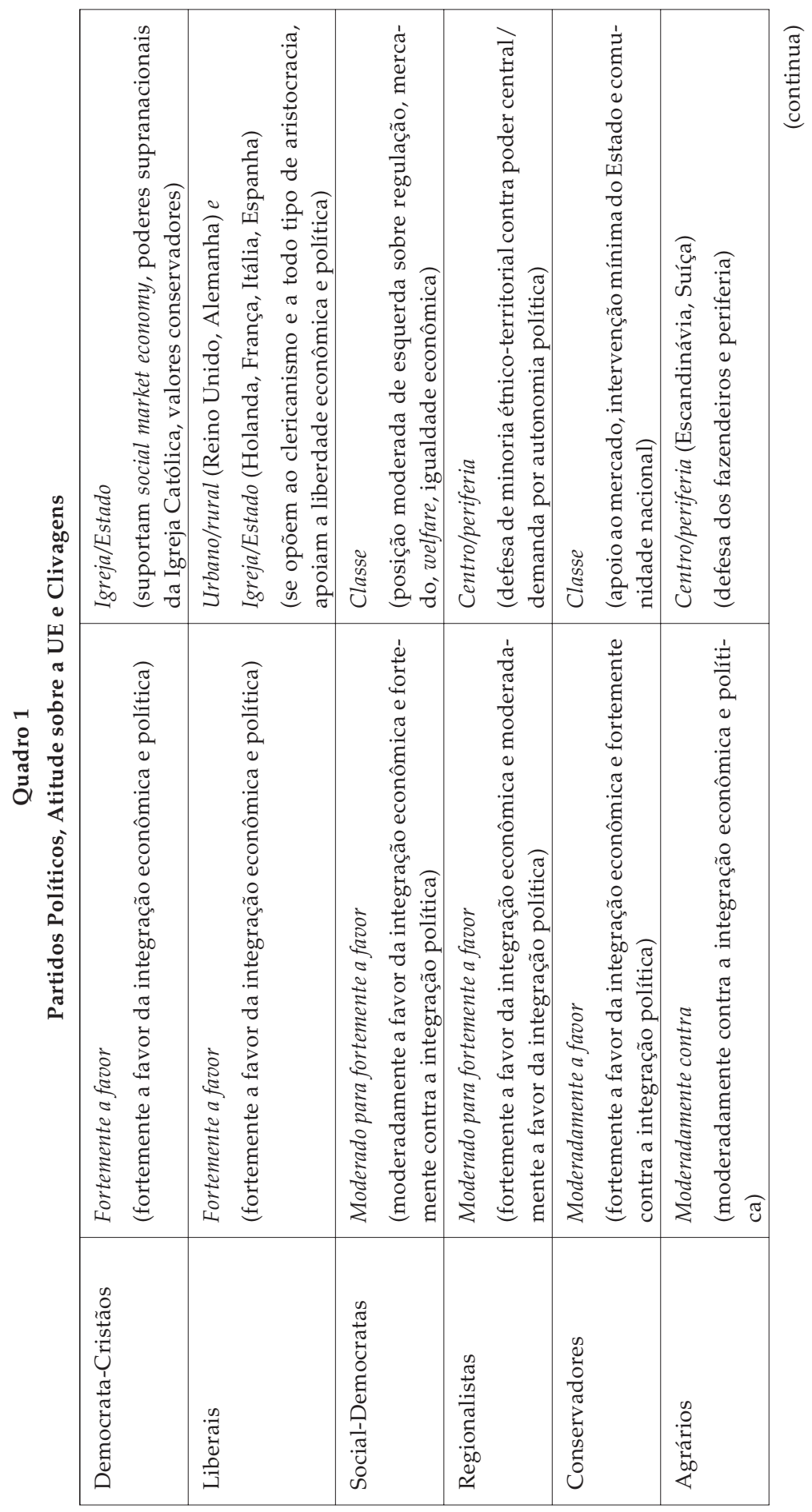


Razões da Intolerância na Europa Integrada

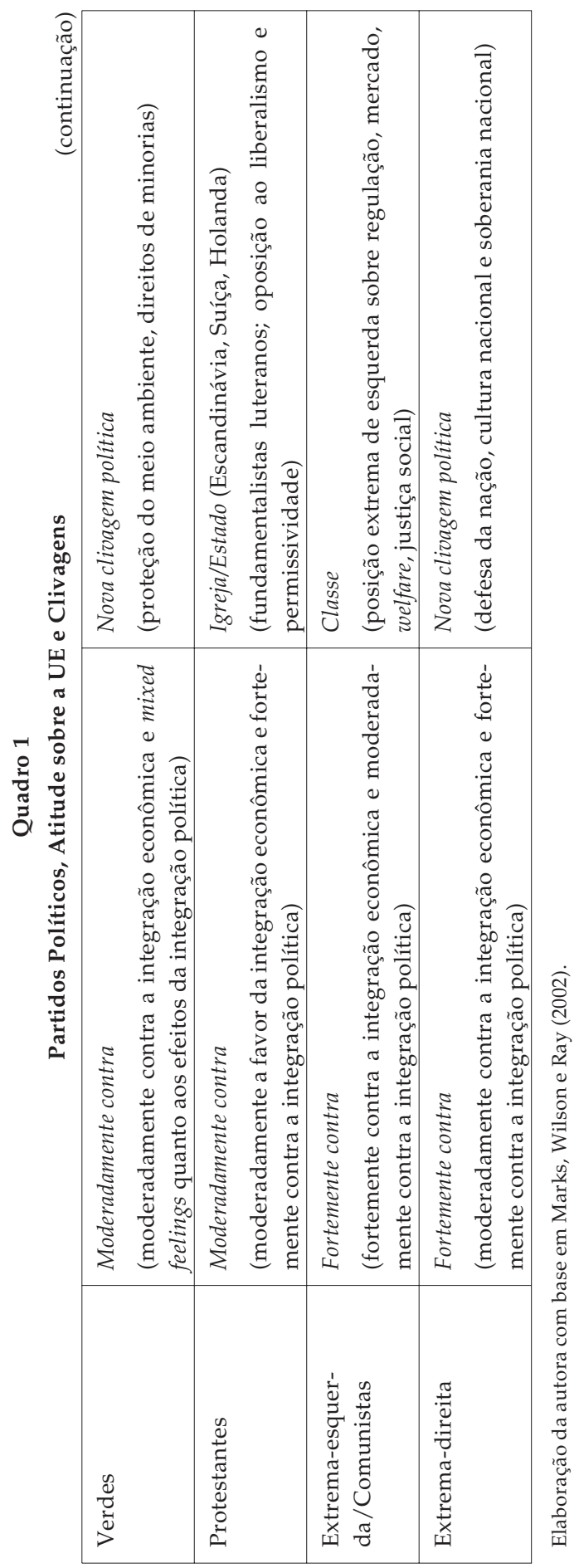


a atuação de partidos políticos de extrema-direita em diversos países. Como o objetivo neste artigo é identificar o real aumento de suporte aos PEDs, além de colaborar para uma melhor compreensão sobre os fatores motivadores desse suporte, primeiramente foram organizados os dados relativos a todas as eleições parlamentares, desde o início da década de 1980 até 2008, para que seja possível verificar o aumento de votos dados a PEDs, desde o surgimento dos mesmos, em toda a região e também por país.

O Gráfico 1 apresenta a soma do percentual de votos atribuídos a partidos de extrema-direita nos países da UE15 e tem o objetivo apenas de propiciar uma visualização sobre a variação do suporte eleitoral recebido pelos PEDs em eleições nacionais na Europa ocidental ${ }^{4}$. A conclusão é que há um crescimento de votos atribuídos a PEDs, com picos de aumento de suporte e períodos de estabilidade. O que mais interessa aos argumentos deste artigo não é o efetivo sucesso eleitoral, no que diz respeito à aquisição de cadeiras nos Parlamentos nacionais, pois os sistemas eleitorais são distintos, com regras específicas em cada um dos países estudados e, em sua maioria, não garantem a possibilidade de pequenos partidos políticos alcançarem votos suficientes para o sucesso eleitoral em Parlamentos nacionais. O objetivo principal é com-

\section{Gráfico 1}

Média de Votos em PEDs (\%)

UE15 (1981-2008)

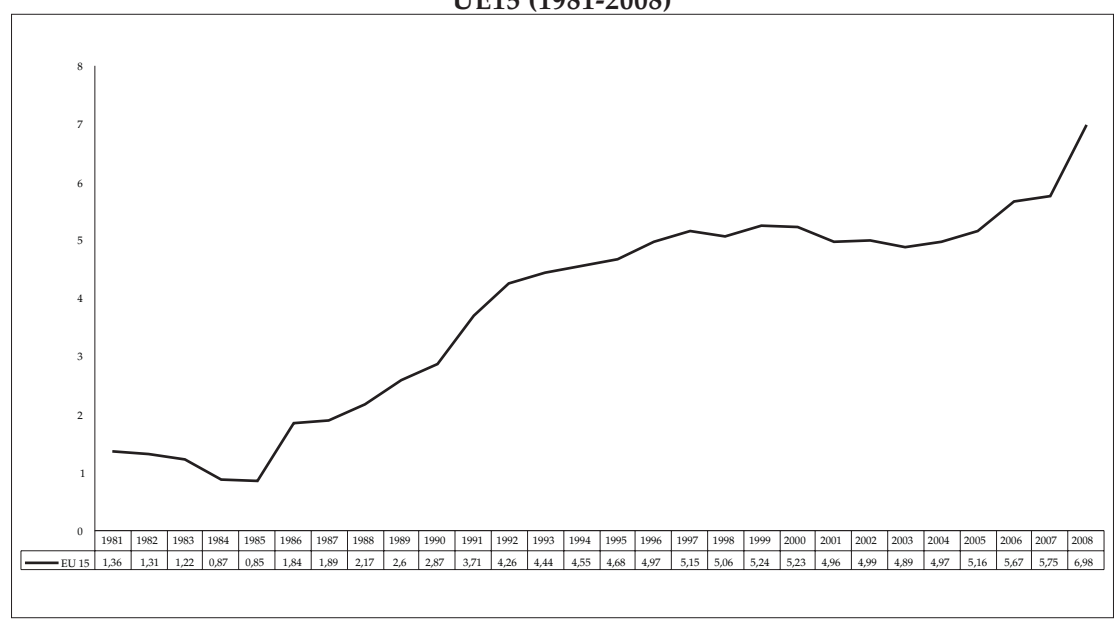

Fontes: http://www.electionworld.org; http:/ /www.electoralgeography.com/new/en/elections; http:/ / www.electionresources.org; http:/ / www.electionguide.org/index.php e sites oficiais de cada país da UE15 (acessados em 10/10/2008). 
provar que a preferência por PEDs está aumentando gradativamente ao longo dos anos investigados. Naturalmente, esse aumento não é distribuído igualmente, pois, em alguns países, os PEDs nem sequer recebem mais do que $0,01 \%$ de votos, logo nem são computados nessa apuração. Por essa razão, mais adiante será necessário distinguir os países que apresentam suporte eleitoral a seus PEDs daqueles que não apresentam. Verificando-se os dados agregados em toda a região no Gráfico 1, vimos que os votos em PEDs cresceram de 1,36\% para 6,98\% quando consideramos a UE15 e todo o período de existência da "nova extrema-direita", qual seja, desde a década de 1980. Apesar de os primeiros PEDs, com as características explicadas acima, terem começado a aparecer no início da década de 1980, só apresentaram resultados eleitorais mais evidentes em 1986 (1,84\%) e mais significativos a partir de 1995 (4,68\%). Nesse período, os PEDs se organizaram melhor e se consolidaram ao longo da década de 1990. O Gráfico 1 ilustra que, após 1995, ocorreu certa estabilização no suporte eleitoral a PEDs em torno de $5 \%$, e desde 2004 um novo crescimento parece despontar.

\section{Gráfico 2}

Votos em PEDs na Alemanha (\%)

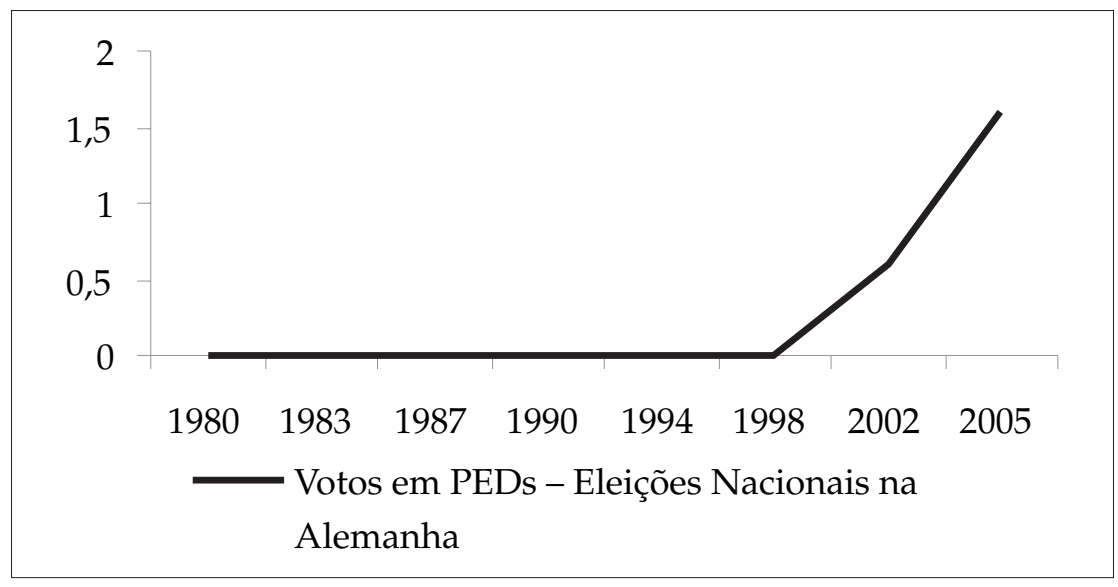

Fontes: http://www.electionguide.org/index.php; http://www.electionworld.org; http: / / www.electoralgeography.com/new/en/elections; http://www.electionresources.org; http://www.bundestag.de/htdocs_e/parliament/elections/election_mp.html (acessados em 10/10/2008). 
Gráfico 3

Votos em PEDs na Áustria (\%)

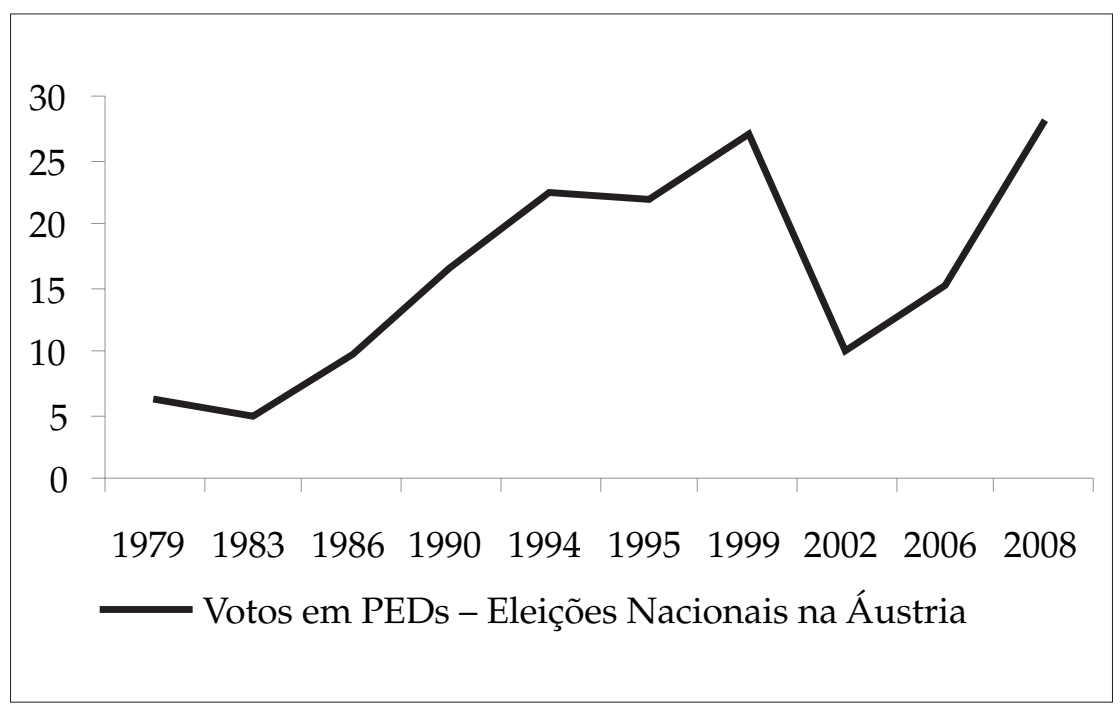

Fontes: http://www.electionguide.org/index.php; http:/ / www.electionworld.org; http://www.electoralgeography.com/new/en/elections; http://www.electionresources.org; e http://www.bundestag.de/htdocs_e/parliament/elections/election_mp.html (acessados em

\section{Gráfico 4}

\section{Votos em PEDs na Bélgica (\%)}

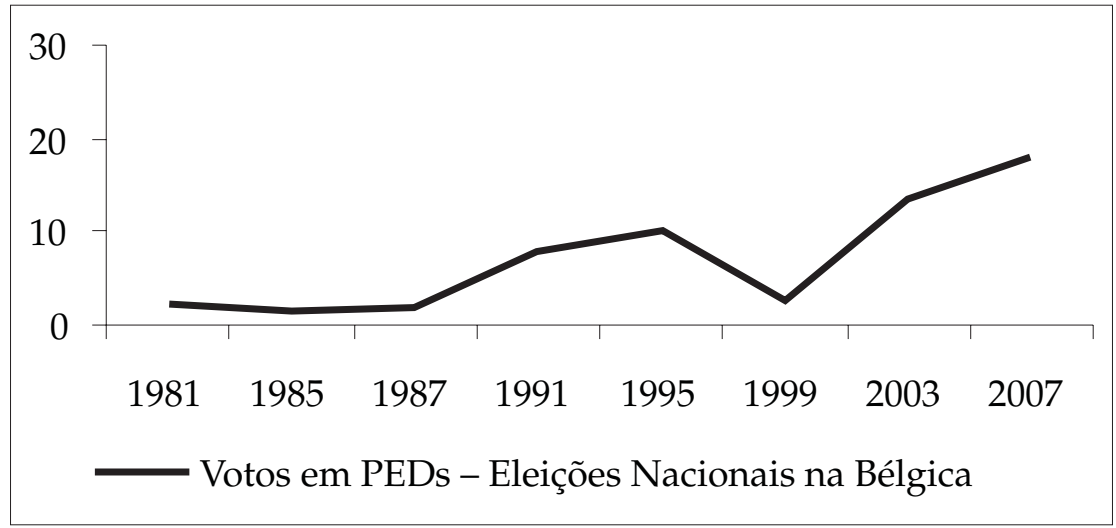

Fontes: http://www.electionguide.org/index.php; http://www.electionworld.org; http:/ / www.electoralgeography.com/new/en/elections; http:/ / www.electionresources.org (acessados em 10/10/2008). 
Gráfico 5

Votos em PEDs na Dinamarca (\%)

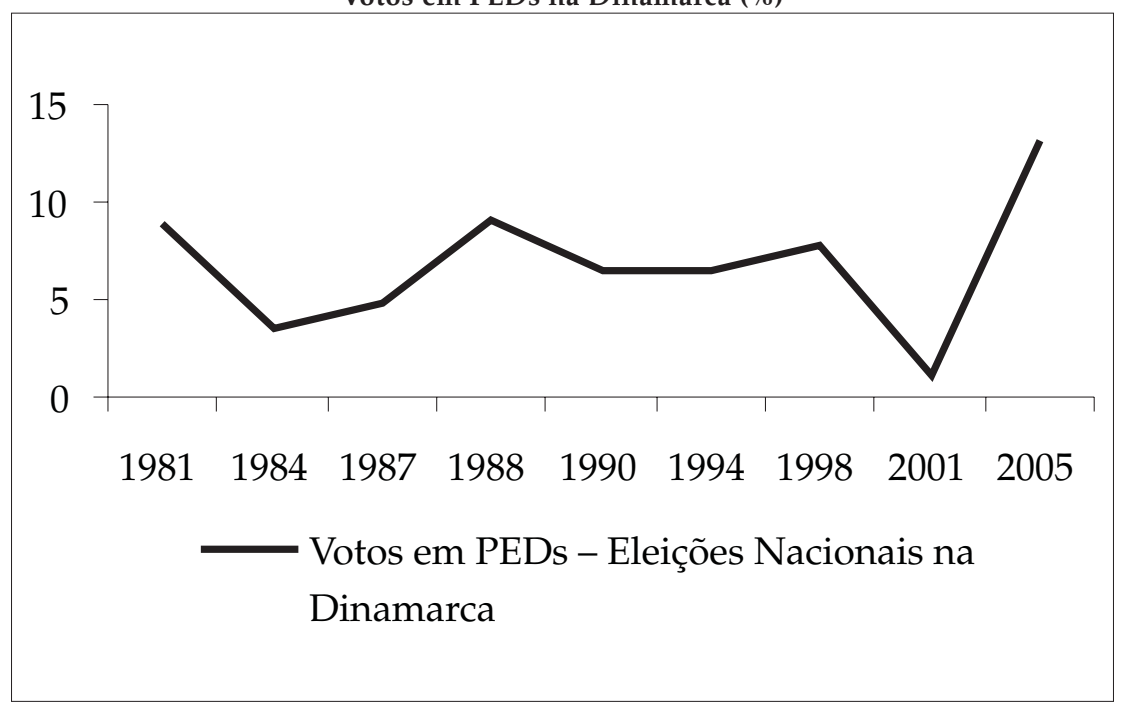

Fontes: http://www.electionguide.org/index.php; http://www.electionworld.org; http:/ / www.electoralgeography.com/new/en/elections; http://www.electionresources.org (acessados em 10/10/2008).

Gráfico 6

Votos em PEDs na Espanha (\%)

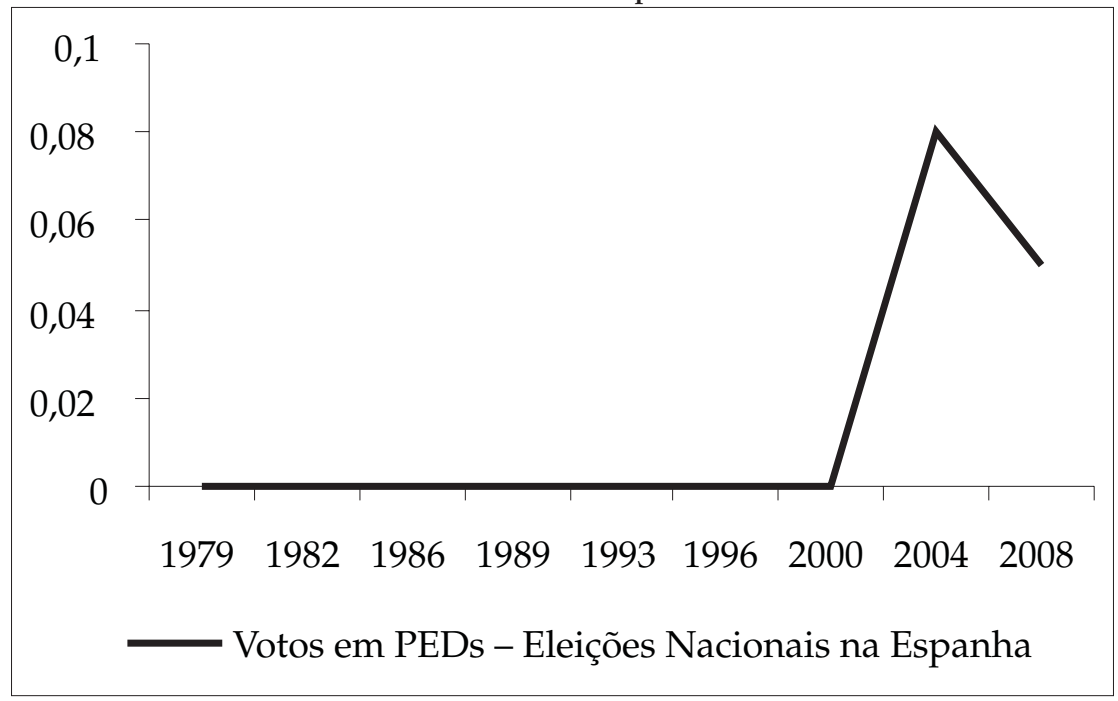

Fontes: http://www.electionguide.org/index.php; http://www.electionworld.org; http:/ / www.electoralgeography.com/new/en/elections; http:/ / www.electionresources.org (acessados em 10/10/2008). 
Gráfico 7

Votos em PEDs na Finlândia (\%)

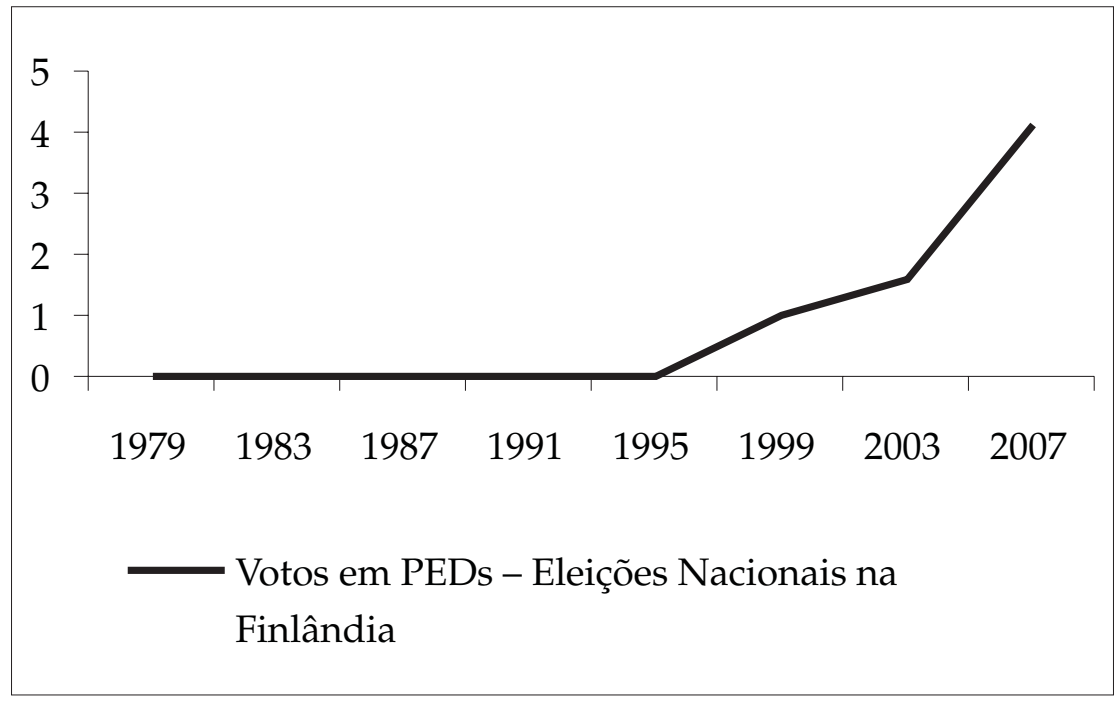

Fontes: http://www.electionguide.org/index.php; http://www.electionworld.org; http:/ / www.electoralgeography.com/new/en/elections; http:/ / www.electionresources.org; http://www.stat.fi/tup/suoluk/suoluk_vaalit_en.html (acessados em 10/10/2008).

\section{Gráfico 8}

Votos em PEDs na França (\%)

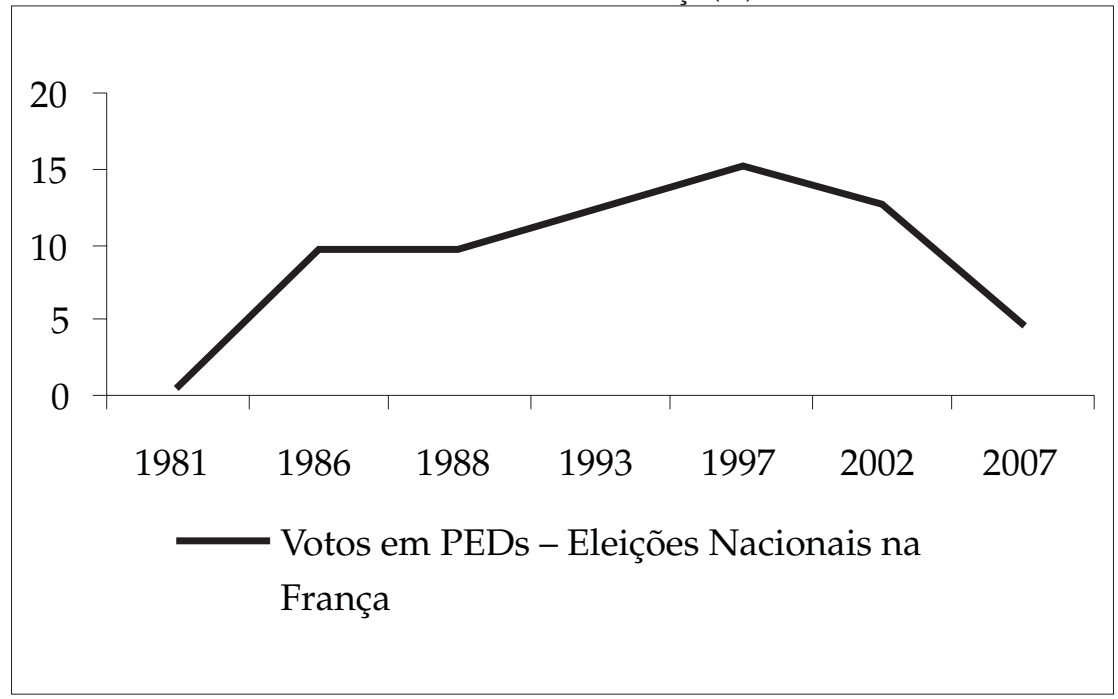

Fontes: http://www.electionguide.org/index.php; http://www.electionworld.org; http:/ / www.electoralgeography.com/new/en/elections; http://www.electionresources.org; http:/ / www.assemblee-nationale.fr/english/index.asp (acessados em 10/10/2008). 
Gráfico 9

Votos em PEDs na Grécia (\%)

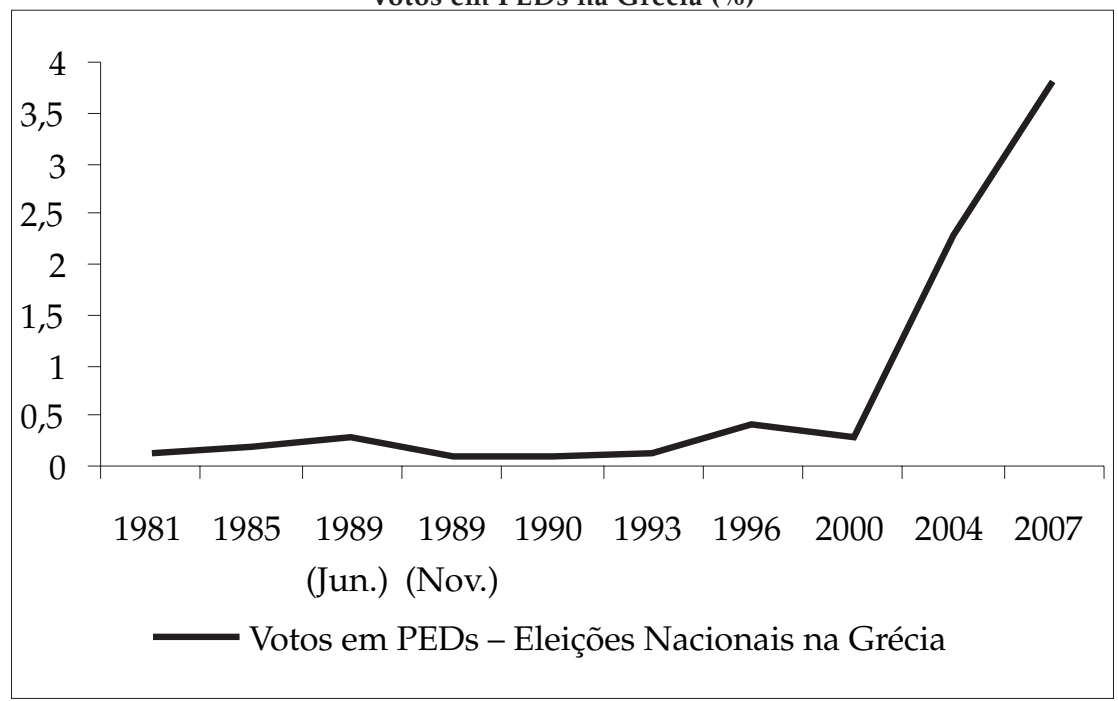

Fontes: http://www.electionguide.org/index.php; http://www.electionworld.org; http://www.electoralgeography.com/new/en/elections; http://www.electionresources.org; http://www.greekelections.com/portal/en/parliam/selectmap.asp?state=parliam (acessados em $10 / 10 / 2008)$.

\section{Gráfico 10}

Votos em PEDs na Holanda (\%)

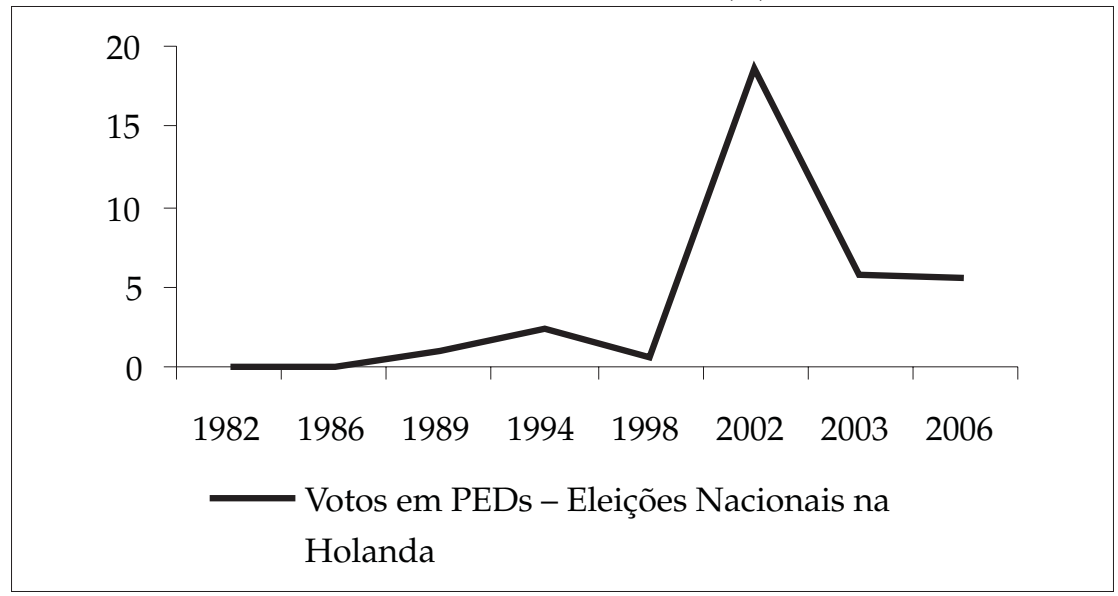

Fontes: http://www.electionguide.org/index.php; http://www.electionworld.org; http:/ / www.electoralgeography.com/new/en/elections; http://www.electionresources.org (acessados em 10/10/2008). 
Gráfico 11

Votos em PEDs na Itália (\%)

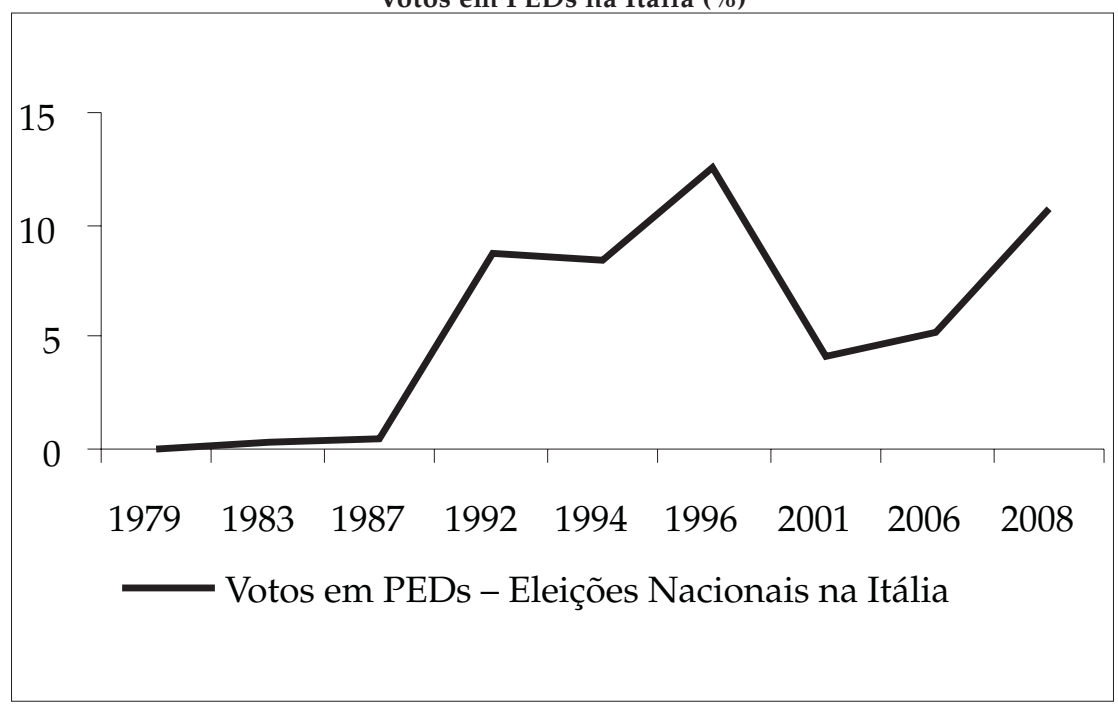

Fontes: http://www.electionguide.org/index.php; http://www.electionworld.org; http:/ / www.electoralgeography.com/new/en/elections; http:/ / www.electionresources.org (acessados em 10/10/2008).

\section{Gráfico 12}

Votos em PEDs na Irlanda (\%)

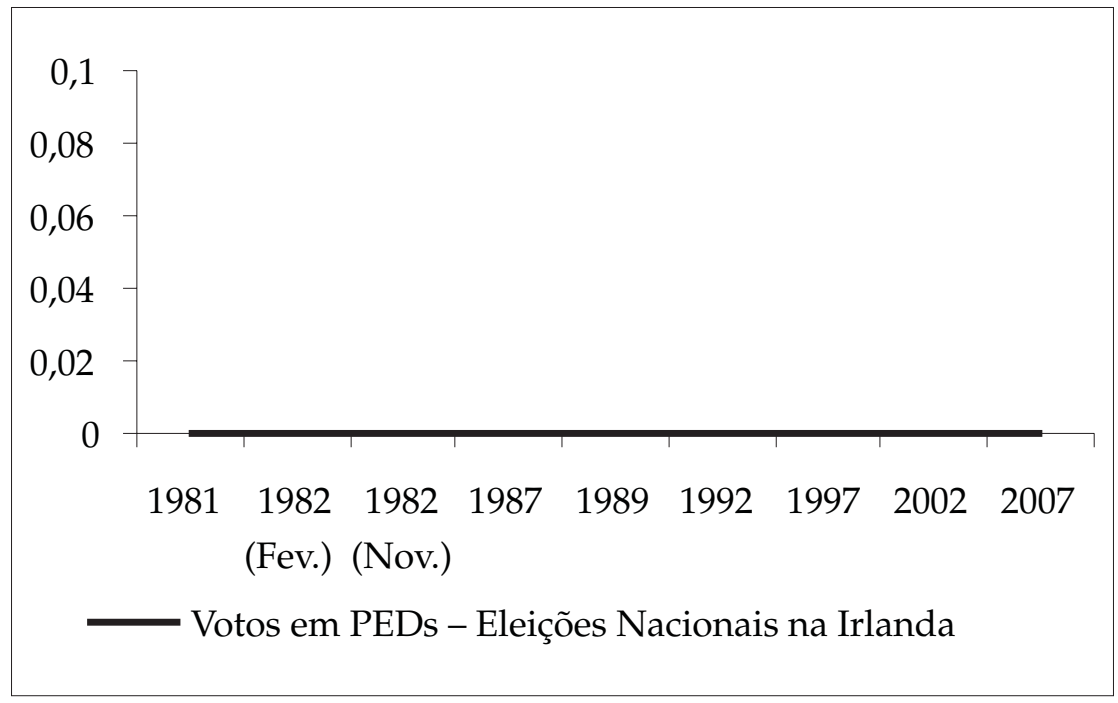

Fontes: http://www.electionguide.org/index.php; http://www.electionworld.org; http: / /www.electoralgeography.com/new/en/elections; http:/ / www.electionresources.org; http://www.electionsireland.org/results/general/index.cfm (acessados em 10/10/2008). 


\title{
Gráfico 13
}

Votos em PEDs em Luxemburgo (\%)

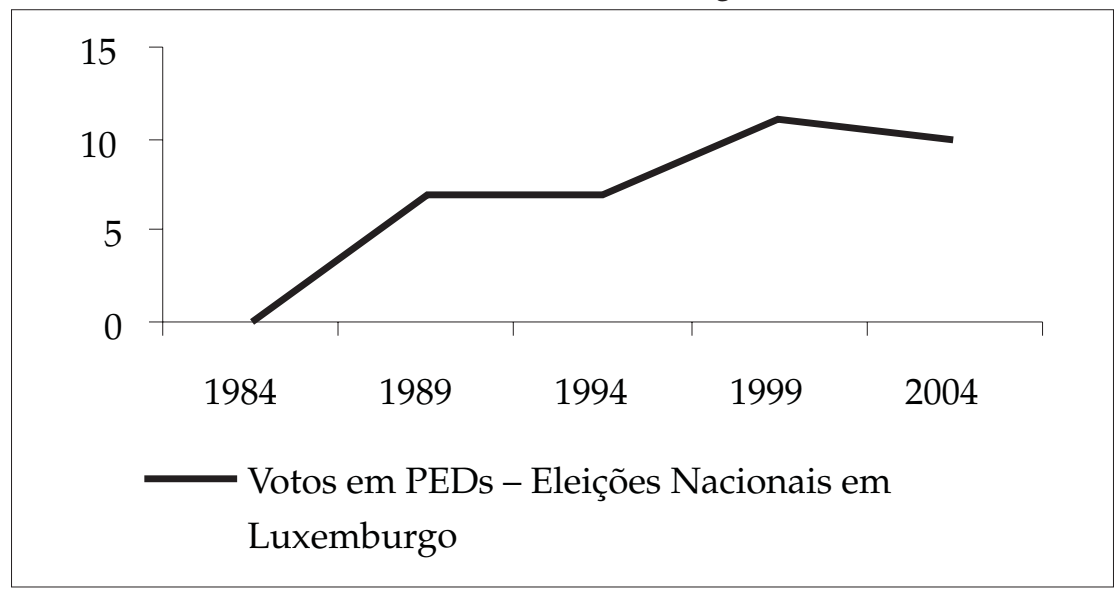

Fontes: http://www.electionguide.org/index.php; http://www.electionworld.org; http:/ / www.electoralgeography.com/new/en/elections; http://www.electionresources.org (acessados em 10/10/2008).

\author{
Gráfico 14
}

Votos em PEDs em Portugal (\%)

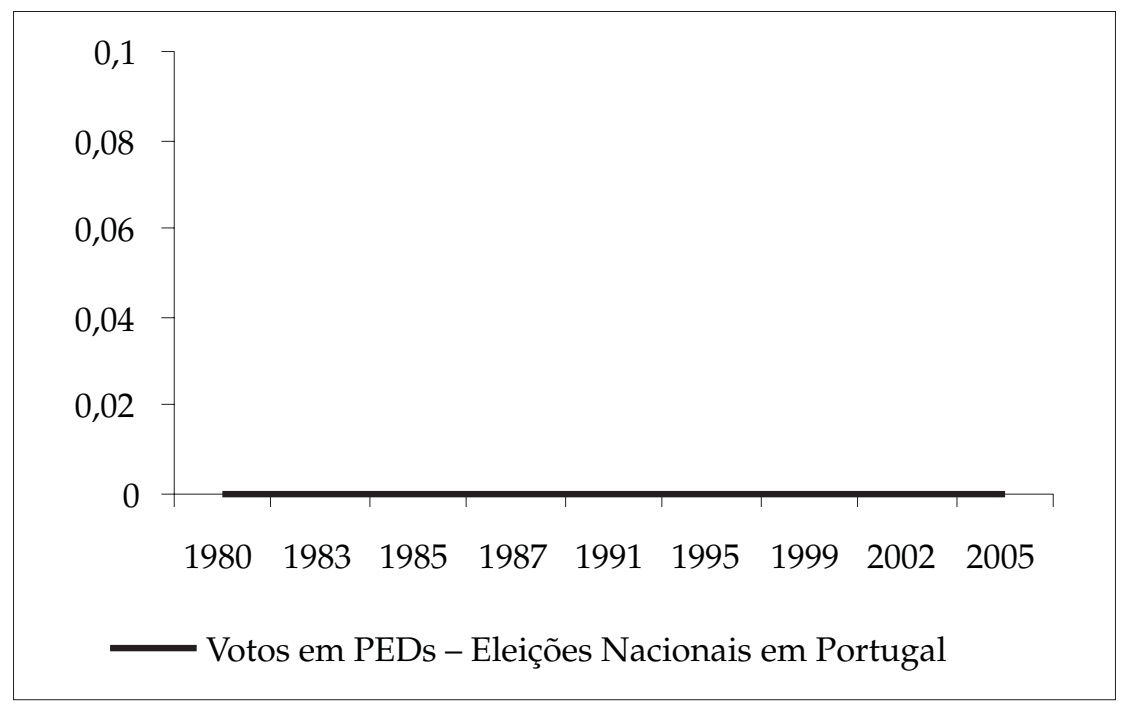

Fontes: http://www.electionguide.org/index.php; http://www.electionworld.org; http:/ / www.electoralgeography.com/new/en/elections; http:/ / www.electionresources.org; http://eleicoes.cne.pt/sel_eleicoes.cfm?m=vector (acessados em 10/10/2008). 


\section{Gráfico 15}

Votos em PEDs no Reino Unido (\%)

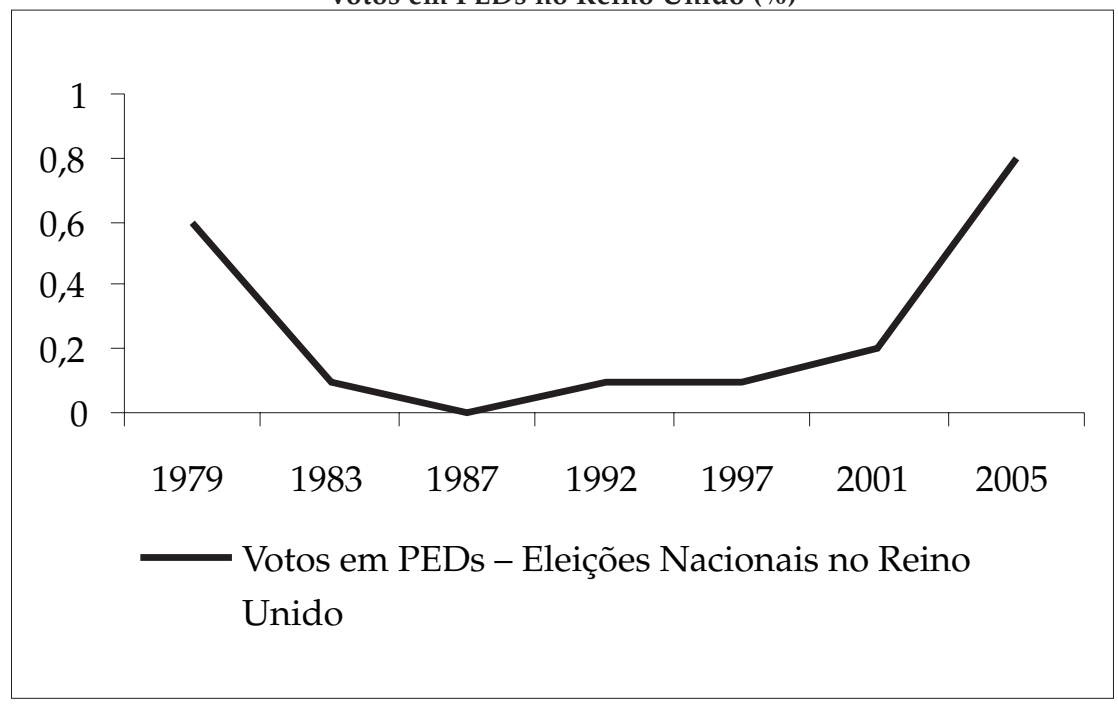

Fontes: http://www.electionguide.org/index.php; http://www.electionworld.org; http:/ / www.electoralgeography.com/new/en/elections; http:/ / www.electionresources.org; http:/ / www.parliament.uk/about/how/elections.cfm (acessados em 10/10/2008).

\section{Gráfico 16}

Votos em PEDs na Suécia (\%)

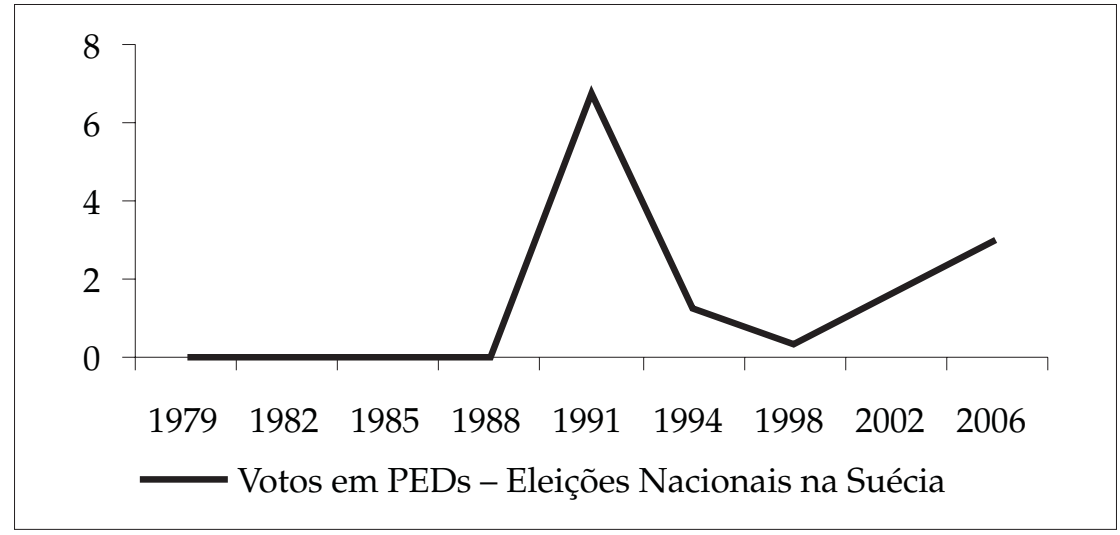

Fontes: http://www.electionguide.org/index.php; http://www.electionworld.org; http:/ / www.electoralgeography.com/new/en/elections; http:/ / www.electionresources.org; http:/ / www.scb.se (acessados em 10/10/2008). 
Quando os países são analisados individualmente, como pode ser visto nos gráficos anteriores, que apresentam o suporte dado aos PEDs por Estado-membro ${ }^{5}$, torna-se possível concluir que, de fato, esse crescimento é uma realidade na quase totalidade dos integrantes da UE15. Luxemburgo apresentou uma pequena queda de 1\% e, na França, desde o susto das eleições de 2002 com a vitória de Le Pen no primeiro turno da disputa para presidência, a Frente Nacional entrou em uma fase de dificuldades. Uma pergunta ainda não respondida pela literatura sobre conjunturas eleitorais que compara performance de partidos políticos na Europa: quais são os motivadores comuns regionais de eleitores que apoiam agendas políticas xenófobas e de resistência à integração política europeia? Sendo o fenômeno do crescimento da extrema-direita comprovadamente regional, consequentemente, os incentivos ao suporte a PEDs não devem ser avaliados com base apenas em conjunturas nacionais. No entanto, ainda resta definir quais variáveis devem ser consideradas entre as atitudes ou percepções, dados ou índices, para uma melhor compreensão da preferência pela defesa da identidade nacional e cultural a qualquer preço. Este artigo não pretende esgotar esse debate, mas sim contribuir com a proposição de variáveis normalmente desconsideradas, como as de representação nas instituições europeias.

\section{CONDIÇÕES E MOTIVAÇÕES}

Os integrantes da UE15 são países de tradições semelhantes e, em função da influência histórica ocidental, possuem instituições nacionais também semelhantes, portanto possuem princípios de organização constitucional e respeito a instituições internacionais comparáveis. O que falta saber é o que há em comum entre as preferências de eleitores, ainda minoritários, por partidos políticos que representam plataformas xenófobas incompatíveis com normas constitucionais e internacionais de respeito às diferenças, à liberdade e aos direitos sociais. Tudo em nome da defesa da soberania e da identidade.

O ano de 2004 foi de muita transparência para os debates a respeito do Tratado da Constituição, de seu conteúdo e da importância em ser aprovado em 2005. Coincidentemente, 2004 e 2005 foram anos em que sete dos países da UE15 tiveram eleições gerais. Desde 2004, no entanto, como se pode verificar no Gráfico 1, é possível identificar um novo fôlego no suporte do eleitor a PEDs - os principais partidos políticos que explicitamente se opuseram ao Tratado da Constituição. O ano de 
2005 foi escolhido então para testarmos variáveis que servirão para a verificação de razões diferentes que teriam levado sociedades envolvidas no processo de integração a ter preferências eleitorais diversas.

Os programas xenófobos dos PEDs se utilizam frequentemente de argumentos em defesa da intolerância, associando a presença crescente da população de imigrantes como elemento determinante de outcomes: aumento da violência, aumento do desemprego, baixo desempenho econômico, entre outros. Diferentemente, a teoria normativa que vem explicando as condições sociais e históricas do aparecimento de uma nova clivagem política, fruto da sociedade pós-industrial, releva o tema da identidade coletiva nos estudos sobre as famílias ideológicas do sistema partidário europeu (Ignazi, 1996; 2003; Kitschelt, 1995).

Quando realizamos estudos comparados isolados entre alguns países da região, verificamos que o que explica algumas causas nacionais para o suporte a PEDs não é capaz de explicar outros casos. Luxemburgo e Bélgica, por exemplo, beneficiaram-se enormemente da integração em termos econômicos; e ainda se tornaram países-chave para a euroburocracia. No entanto, apresentam uma alta média de suporte, por parte de seus eleitores, aos PEDs. Baixíssimos índices de desigualdade de distribuição de renda e aumento de emprego são realidades nacionais, em ambos os casos, que não ajudam a compreender as razões da intolerância nesses países. Ao contrário, a Alemanha vem sofrendo consequências de sua integração nacional e regional ao longo dos últimos anos, com altos índices de desemprego e de imigração, por exemplo. Contudo, a população votante na Alemanha apresenta um baixíssimo suporte a PEDs. Esses foram alguns exemplos que buscam justificar a necessidade da investigação sobre causas comuns regionais que contribuem para a compreensão do aumento de votos em PEDs na Europa ocidental.

Ao considerarmos as tradições de suporte e não suporte a PEDs em países ocidentais europeus, percebemos que o desempenho econômico não é um bom indicador para a explicação da ausência de suporte a PEDs. Casos contrastantes como Irlanda e Portugal - países sem nenhuma tradição de suporte a PEDs - apresentaram crescimento econômico completamente diverso em 2007 (Irlanda com o mais alto índice de crescimento, $5 \%$, e Portugal com o mais baixo, 1,8\%). 
Tabela 1

Média de Votos em PEDs

(1981-2008)

\begin{tabular}{l|c}
\hline UE15 & $\mathbf{1 9 8 1 - 2 0 0 8}$ \\
\hline Alemanha & $\mathbf{( \% )}$ \\
Áustria & 0,3 \\
Bélgica & 15,1 \\
Dinamarca & 6,9 \\
Espanha & 8,5 \\
Finlândia & 0 \\
França & 0,7 \\
Grécia & 9,6 \\
Holanda & 1,1 \\
Irlanda & 2,5 \\
Itália & 0 \\
Luxemburgo & 5,1 \\
Portugal & 6,3 \\
Reino Unido & 0 \\
Suécia & 0,3 \\
\hline
\end{tabular}

Fontes: http://www.electionworld.org; http://www.electoralgeography.com/ new/en/elections; http://www.electionresources.org; http://www.electionguide. org/index.php e sites oficiais de cada país da UE15 (acessados em 10/10/2008).

A Tabela 1 demonstra a média de votos atribuídos a PEDs por país ao longo dos 28 anos pesquisados ${ }^{6}$. Como pode ser visto nos Gráficos $12 \mathrm{e}$ 14 e na Tabela 1, tanto na Irlanda quanto em Portugal, PEDs não vêm conseguindo se organizar e/ou receber suporte eleitoral de expressão. No caso de Portugal, temos observado o Partido Nacional Renovador (PNR) buscar sustentação eleitoral sem sucesso, provavelmente por representar uma tradicional extrema-direita, sem a renovação representada pela nova clivagem política que apoia o novo radicalismo de direita. A Tabela 1 demonstra todas as médias dos percentuais de votos atribuídos à totalidade de PEDs em cada Estado-membro da UE15 no período de emergência e de consolidação dos PEDs até as últimas eleições nacionais (2008). Como se observa, apesar de não serem países que possuam tradicionalmente fortes PEDs, Reino Unido, Alemanha, Finlândia e Grécia eventualmente veem uma minoria bastante peque- 
na de seus eleitores votando em agendas extremistas. Contrariamente, Luxemburgo, Bélgica e Dinamarca, por exemplo, já vêm se alinhando aos países de tradição de suporte a PEDs, como a Áustria. Espanha é um dos países europeus ocidentais com mais forte tradição de organização de grupos xenófobos em networks, no entanto, a organização partidária de extrema-direita espanhola ainda é fraca.

Enfim, Espanha, Irlanda e Portugal não apresentam absolutamente condições para o aparecimento de PEDs fortes, pois a média de votos atribuídos a PEDs nesses três países, desde a década de 1980, é “0” (ver Tabela 1). O que explicaria a diferença de motivações ou receios entre as sociedades que não absorveram o euroceticismo em nenhum grau?

Com a finalidade de desvelar condições sociais e institucionais que poderiam influenciar a preferência eleitoral pelos PEDs, foram selecionadas algumas variáveis para correlação com o suporte aos PEDs. A finalidade é contribuir para uma mais afinada compreensão sobre a relação de indicadores de desempenho econômico, aumento de criminalidade, capacidade de representação e atitudes sobre a UE e suas reformas, com a eventual existência de suporte aos PEDs. Consideramos que o exercício de reflexão e pesquisa a respeito dos caminhos até então percorridos pelo euroceticismo na Europa é fundamental para a compreensão da atual crise da UE, em que reformas institucionais dependem do convencimento das sociedades de que a integração interessa a todos e reformas regionais já implementadas buscam legitimação social.

\section{HIPÓTESE E VARIÁVEIS}

A agenda de integração social e política da UE só é combatida fortemente pelos PEDs (ver Tabela 1), e as plataformas eleitorais nacionais desses partidos vêm refletindo uma constante e clara atitude intolerante quanto às consequências da integração política. Por ser o aumento de votos em PEDs um fenômeno regional, fatores isolados nacionais ou conjunturais que consideram eleições isoladas não são suficientes para uma explicação que abranja o significado do crescimento da extrema-direita em toda a região ocidental europeia.

Treze variáveis foram selecionadas para serem aplicadas a um teste de médias entre grupos de países cujos eleitores apresentam tradição de suporte a PEDs e países em que os eleitores não apresentam essa tradição. O objetivo na seleção das variáveis foi reunir aspectos sociais, 
econômicos e de representação, bem como acolher variáveis de percepção regularmente usadas na literatura sobre euroceticismo que possam colaborar para o teste da hipótese de que o crescimento da extrema-direita não está associado a benefícios econômicos e materiais trazidos pela UE, tampouco pode ser compreendido em estudos comparados de casos isolados. Em outras palavras, o suporte a PEDs na Europa não se explica por motivos econômicos nem puramente nacionais; e, por isso, as escolhas eleitorais em eleições nacionais em toda a região ao longo das etapas de consolidação do processo de integração revelam motivações para a atitude eurocética do eleitor europeu.

Alguns dos fatores mais comuns de observação e de pesquisas de opinião pública europeia sobre euroceticismo são as atitudes de falta de confiança na UE e em suas instituições e, mais recentemente, a atitude $a$ favor ou contra o Tratado da Constituição Europeia, que, após as rejeições da França e da Holanda, ocorridas em 2005, falhou em seu projeto de aprovação. Julgamos, por conseguinte, o nível de informação sobre as instituições europeias importante para que consideremos a eventual conscientização sobre o papel das instituições europeias e as mudanças ocorridas nos órgãos políticos nacionais por via da integração política e suas reformas. Um bom exemplo da valorização do papel da informação na mensuração do euroceticismo já foi identificado pelos analistas das pesquisas do Eurobarometer 65 (2006) a respeito do suporte ao Tratado da Constituição Europeia. Segundo o Eurobarometer 65 (2006), a falta de suporte ao Tratado da Constituição pode ser atribuída à falta de informação. A variável informação sobre as instituições europeias significa "o quanto as sociedades nacionais se consideram bem informadas a respeito do processo de integração e do papel das instituições europeias". É importante mencionar, no entanto, que essa variável de percepção não deve traduzir a efetiva consciência sobre as consequências da existência de instituições europeias, mas informar o padrão de satisfação a respeito do conhecimento sobre a $\mathrm{UE}^{7}$.

Duas variáveis de representação institucional foram selecionadas para o teste: o peso dos votos no Conselho e o número de assentos no Parlamento Europeu. Esses dados estão organizados em função do percentual de peso que cada país possui em cada instituição europeia, levando-se em consideração o total de votos e de assentos de todos os países-membros da UE. A verificação da capacidade de representação dos países nas instituições europeias pode ser um importante indício de quanto o Estado-membro exerce influência no processo decisório europeu. É es- 
perado que as sociedades que vêm dando suporte aos partidos que resistem à integração possuam menor representação nas instituições europeias, reforçando-se assim a insatisfação quanto à capacidade de interferência no processo decisório europeu e consequente redução de instrumentos de defesa da soberania e da cultura nacionais.

As variáveis econômicas de desemprego e desigualdade de distribuição de incomes foram construídas a partir de dados do Eurostat Yearbook (2005) e contribuem para a configuração das condições de desempenho econômico que afetam diretamente a percepção do eleitor, sobretudo em virtude da existência de estrangeiros e imigrantes que disputam espaços de trabalho e outros ambientes de convívio social.

As variáveis sobre violência - dez crimes comuns 2004-2005, ou seja, 2005 em relação ao ano imediatamente anterior, dez crimes comuns nos últimos cinco anos, roubo 2004-2005, roubo nos últimos cinco anos e, finalmente, crimes de ódio - são relevantes para verificar se há alguma relação entre a preferência pelas agendas intolerantes em relação a imigrantes e a estrangeiros e o aumento da violência. A decisão pela inclusão dessas variáveis de risco social e de vitimização foi uma consequência da observação dos programas dos PEDs, que frequentemente apelam para a associação entre o aumento da violência e a justificativa da atitude intolerante no que se refere aos imigrantes e estrangeiros. É importante destacar que a violência diminuiu na região da UE15 em geral, e os dez crimes mais comuns ou frequentes nos países europeus apresentam uma significativa redução de incidência nos últimos anos na maioria dos países pesquisados.

Os dados utilizados para a mensuração das variáveis sobre violência foram fornecidos pela European Crime and Safety Survey (EU ICS), publicada como EU Research Report - ICS em 2005 (Van Dijk et alii, 2005). Essa extensa survey buscou produzir estimativas de vitimização para serem usadas em perspectiva comparada, envolvendo os países da UE15 e mais três dos novos países do Leste Europeu (Polônia, Estônia e Hungria). Os dez crimes mais frequentes em cada país foram pesquisados conjuntamente, e foi considerada na survey a incidência de uma ou mais vitimização nos últimos cinco anos (antes de 2005) e entre os anos de 2005 e 2004, excluindo-se o crime de roubo, que teve um tratamento separado. Especificamente, a inclusão dos crimes de ódio como variável explanatória teve o objetivo de incluir os crimes considerados ma- 


\section{Gráfico 17}

Nível de Confiança nas Instituições Europeias (\%)

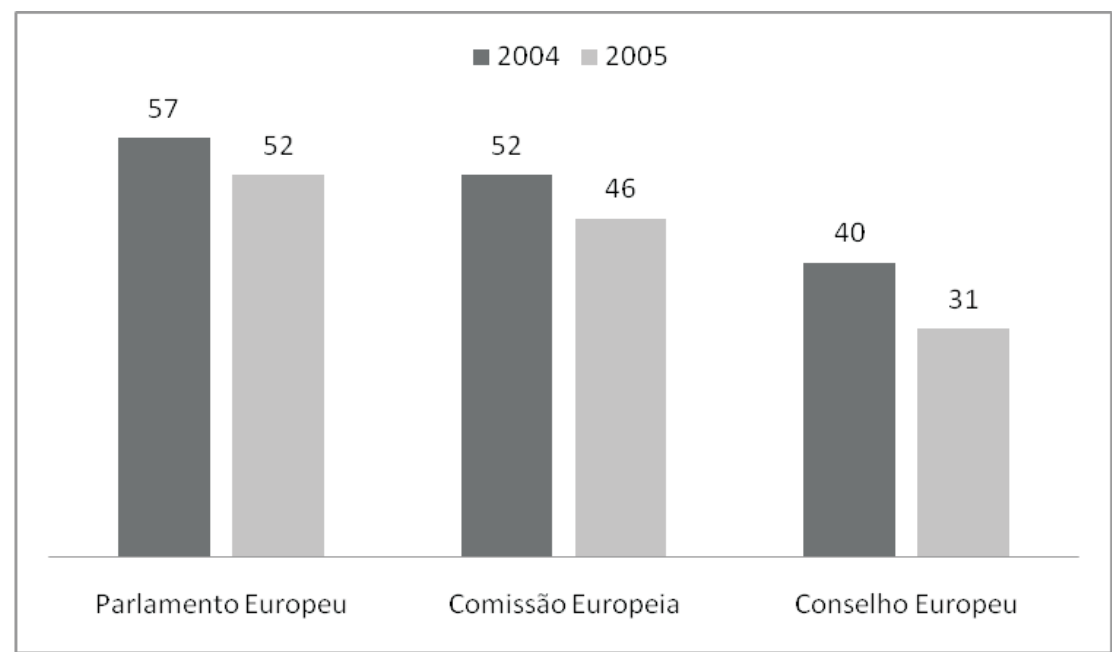

Fonte: Eurobarometer 63 (2005).

joritariamente contra imigrantes e outras minorias, logo, fundamental para os argumentos deste artigo.

A variável população imigrante foi considerada importante para a identificação da presença de uma significativa população imigrante em relação à alta média existente na UE15. Foram considerados os percentuais da população imigrante por país usando-se dos dados publicados pelo Europäisches Migrationszentrum (EMZ) ${ }^{8}$. O objetivo da utilização dessa variável é identificar a eventual presença de imigrantes, acima da média ou não, em países onde o programa de PEDs é mais convincente.

Consideramos que os dados pesquisados sobre o suporte a PEDs, desde seu surgimento na década de 1980, associados às variáveis sobre representação, desempenho econômico, vitimização e população imigrante, são fundamentais para uma contribuição ao debate sobre as razões ainda pouco conhecidas que têm levado os eleitores a se voltarem cada vez mais, ainda que minoritariamente, para plataformas políticas xenófobas. Sabendo-se que a atitude extremista de direita também reflete a resistência à integração europeia, a crítica populista à falta de legitimidade do processo de integração se reforça e lentamente vem aumentando. 
Como se pode observar no Gráfico 17, o nível de confiança nas instituições europeias vem diminuindo. A Irlanda, por exemplo, um dos países que apresentava menos resistência à Constituição Europeia, ao lado de Portugal e Espanha em 2000 (Eurobarometer 53, 2000), recentemente rejeitou o Tratado de Lisboa, que nada mais é do que uma versão resumida e enxuta do Tratado da Constituição.

\section{MEDINDO EFEITOS}

Dividindo os países da UE15 em dois grupos, foi aplicado um teste estatístico simples, de médias, com o objetivo de verificar que variáveis produziriam impacto sobre a performance dos PEDs. Foram selecionados dados de 2005 para as variáveis do teste, por ser considerado um ano importante para o crescimento geral do suporte a PEDs, como pode ser conferido no Gráfico 1. Assim, o grupo A está constituído dos países em que as sociedades nacionais não vêm apresentando suporte eleitoral a PEDs desde 1980. Em outras palavras, países em que a média de votos atribuídos à extrema-direita é " 0 " (ver Tabela 1 ). O grupo B está constituído dos países em que as sociedades apresentam, mais ou menos intensamente, suporte eleitoral a PEDs. Testando-se as diferenças de médias encontradas em cada grupo de países, espera-se que fatores relacionados a desempenho econômico de fato não sejam fundamentais para explicar a diferença de suporte dado pelas sociedades nacionais dos países do grupo A quando comparados aos países do grupo B.

O teste de médias utilizado ${ }^{9}$ é adequado para responder se as médias dos dois grupos de países, em virtude das variáveis utilizadas, são estatisticamente diferentes. Ou seja, se os países com diferentes níveis de suporte eleitoral a PEDs apresentam resultados efetivamente divergentes em relação às variáveis de representação, às variáveis econômicas e sociais utilizadas. Quanto às variáveis mais comumente usadas pela literatura sobre euroceticismo (falta de confiança na UE e contra a Constituição Europeia), espera-se que o grupo B de fato apresente menos confiança na UE e seja mais resistente a reformas como a da Constituição Europeia - o que caracteriza uma eurocética mais geral.

Quanto às variáveis sobre violência, espera-se que a violência tenha diminuído em menos intensidade ou grau nos países cujos eleitores apresentam algum suporte a PEDs. Isso porque a preferência pelo voto intolerante tem sido genericamente associada à percepção de que as 
sociedades estão em risco e a criminalidade estaria refletindo a não inclusão do imigrante indesejado pelo eleitor xenófobo. Outra consequência da fragmentação social e da não integração do imigrante é a discriminação e mesmo o aumento dos "crimes de ódio", que são vistos como uma reação exacerbada da intolerância, da rejeição e da discriminação. Assim, espera-se que haja mais crimes de ódio nos países do grupo B.

Na sequência lógica do que já se compreende a respeito do comportamento xenófobo, espera-se que a população imigrante em países em que PEDs recebem mais apoio seja maior, apesar de Luxemburgo, país de baixa incidência de suporte a PEDs e também de crimes de ódio, ser o país que abriga uma população imigrante largamente maior do que a média europeia (cerca de $37 \%$ da população de Luxemburgo é constituída de imigrantes).

É importante salientar que, embora o teste de médias utilizado não constitua um teste estatístico sofisticado, ele é um exercício matemático e estatístico útil, capaz de evidenciar argumentos e de complementar a tese sobre as razões não materiais que explicam a performance de PEDs. Assim, o objetivo da inclusão de um teste de médias, como o apresentado na Tabela 2, é apenas para que a análise ganhe um instrumento descritivo útil, capaz de evidenciar, com maior grau de robustez, as diferenças entre as médias dos grupos dos países estudados. Por essa razão, a variável dependente do teste é o suporte dos eleitores, ainda que eventual e minoritário, a PEDs em países europeus ocidentais. Chamamos de suporte "a atitude de votar em PEDs", independentemente do efetivo sucesso eleitoral em termos de aquisição de assentos nos Parlamentos nacionais.

O primeiro resultado do teste de médias realizado que merece destaque é que os países do grupo B apresentam uma média de atitude contra a Constituição Europeia e de falta de confiança na UE maior do que os do grupo A, $49 \%$ para $13 \%$ e $49 \%$ para $0,29 \%$, respectivamente. As duas médias são estatisticamente diferentes, com nível de confiança máxima. Esses resultados sugerem, como era esperado, uma forte correlação entre a atitude de desconfiança na UE e a atitude de não suporte quanto às reformas e ao aprofundamento do processo de integração política. O Tratado da Constituição Europeia e a decisão pelas ratificações populares a partir de amplos debates constituíram uma medida de busca de legitimação ex post do processo de integração. O próprio 


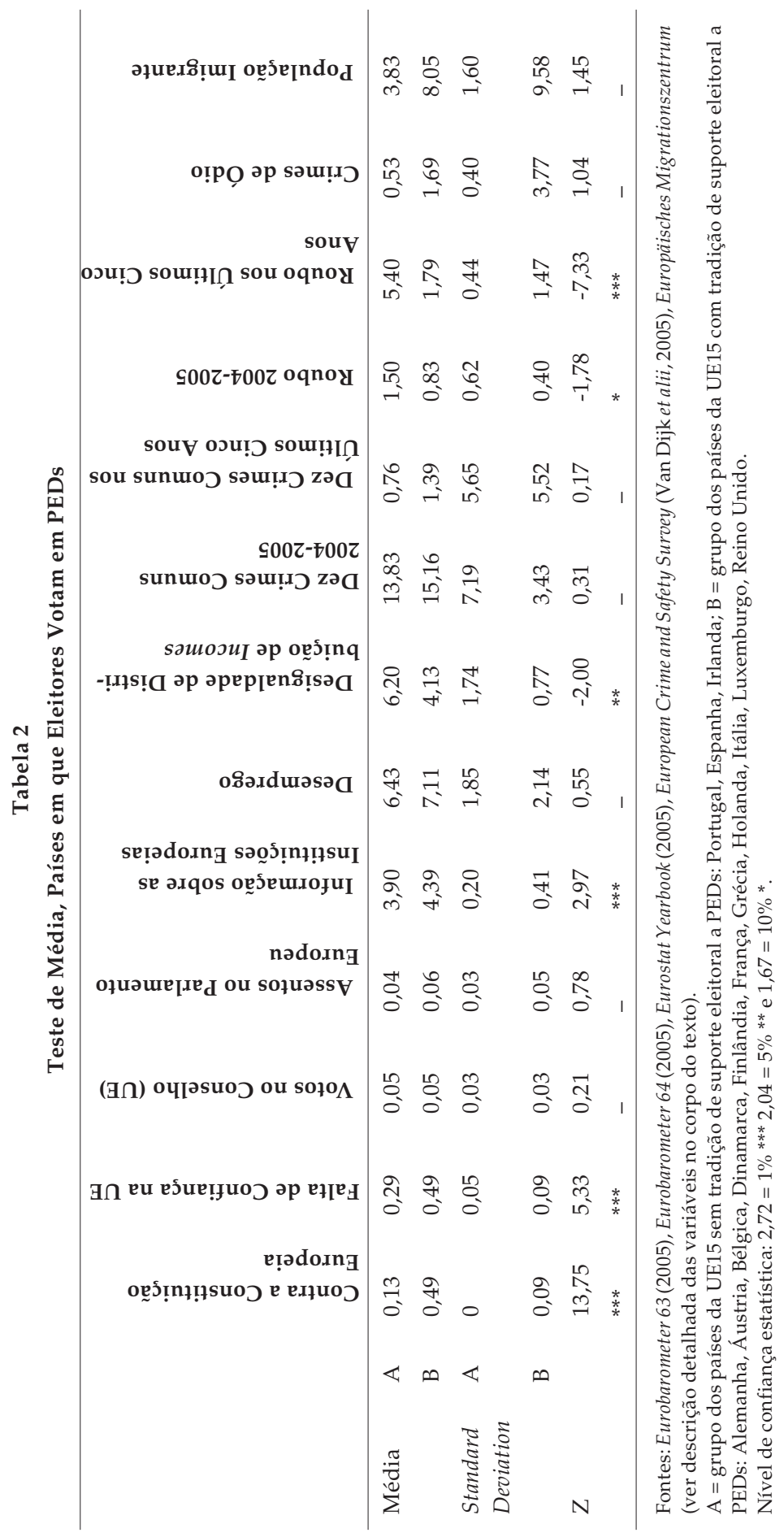


apelido de "Constituição" dado ao Tratado de Roma é o sinal mais evidente da intenção em se efetivar uma aproximação da integração que vem sendo realizada entre elites políticas com a participação mais ampla e consciente das sociedades europeias. Assim, a atitude de não suporte à ratificação desse tratado está fortemente associada à atitude de desconfiança mais generalizada quanto a UE.

O segundo resultado é o que se refere às variáveis de representação dos países-membros nas instituições europeias. As diferenças de médias, nesse caso, não apresentaram relevância estatística, mas, diferentemente das expectativas, apresentaram resultados positivos. O grupo dos países cujos eleitores mais tradicionalmente suportam PEDs possuem mais cadeiras no Parlamento Europeu e mais votos no Conselho, logo, possuem mais instrumentos de interferência nas decisões sobre as políticas regionais. Como a mudança no número de cadeiras e de votos no Conselho é muito pouca, e os dados, no caso dessas variáveis, variam mais raramente do que os demais, um exercício econométrico que considerasse uma série temporal longa seria mais preciso, o que poderia tornar os efeitos dessa variável mais esclarecedores.

Um resultado considerado relevante ao suporte dos argumentos deste artigo é o que se refere à variável informação sobre as instituições europeias. O grupo B apresenta uma média maior do que o grupo A, 3,9\% para $4,39 \%$, respectivamente, sendo a diferença dessas médias de nível máximo de confiança estatística no teste, ou seja, a 1\%. Esse resultado sugere que as sociedades nacionais dos países do grupo B são significativamente mais bem informadas sobre a UE do que as sociedades nacionais dos países do grupo A. De outra forma, as sociedades nacionais que votam, ainda que eventualmente, em PEDs são mais conscientes a respeito do papel das instituições europeias ou das consequências da integração europeia em geral quando comparadas com as sociedades nacionais dos países do grupo A. Esse resultado é bastante interessante para a sustentação de argumentos sobre a relação entre a preferência do voto por partidos que se opõem à UE e a percepção de conhecimento e satisfação quanto à informação sobre os efeitos e as funções das instituições europeias. Isso sugere que o voto em PEDs pode significar um voto de resistência consciente à UE, uma vez que esses são os únicos partidos políticos europeus fortemente contra a integração política que vêm apresentando crescimento de votos ${ }^{10}$. 
A diferença de médias da variável econômica desemprego não apresentou relevância estatística, mas é positiva. $O$ desemprego vem sendo fortemente associado ao crescimento da extrema-direita em diversos importantes trabalhos; porém, o alto desemprego, na maioria dos países europeus, não pode ser analisado sem a consideração da proteção garantida pelo ainda forte Welfare State europeu. Assim, consideramos a variável desigualdade de distribuição de incomes possivelmente mais importante do que desemprego nesse teste, que não considera os "benefícios" percebidos do cidadão desempregado, que variam na Europa de país para país. A variável desigualdade de distribuição de incomes apresentou um resultado negativo, com diferença estatística relevante e nível de confiança bastante alto, muito próximo a $5 \%$. Os países do grupo $\mathrm{B}$ apresentam uma média de desigualdade de distribuição de renda significativamente menor do que os do grupo A, de $4,13 \%$ para $6,2 \%$. Esse resultado sugere que as sociedades menos afetadas por fragmentações sociais provindas da má distribuição de renda têm votado mais em partidos xenófobos na Europa ocidental. Isso contradiz os argumentos que associam desigualdade social à atitude intolerante.

Foram testadas variáveis sobre violência tendo-se em conta a genérica associação que discursos xenófobos costumam fazer em relação ao problema da violência urbana, e, no teste, encontramos um resultado bastante sugestivo. Além do fato de que a violência vem diminuindo em toda a região da Europa ocidental, como já visto anteriormente, no caso dos países do grupo B, os crimes de roubo diminuíram significativamente no último ano considerado para a pesquisa do European Crime and Safety Survey (EU ICS 2005). Considerando-se ainda os índices dos últimos cinco anos precedentes à pesquisa de 2005, a diferença da diminuição de roubos entre os grupos A e B se torna extremamente relevante. Ou seja, existe uma maior diminuição dos crimes de roubo nos países do grupo $B$ com uma diferença estatística significativa máxima no teste (nível de confiança a 1\%). Ou seja, no grupo B, constituído de sociedades que, ainda que eventual e minoritariamente, suportam PEDs e votam em agendas xenófobas, os crimes de roubo têm diminuído mais significativamente do que nos países onde não existe suporte a PEDs. Lembrando que os programas e discursos de líderes de PEDs associam a desigualdade, o desemprego e a criminalidade à necessidade da defesa de uma agenda xenófoba. Curioso é que, ainda que sem relevância estatística, podemos conferir que, ao contrário dos crimes de roubo, no caso dos crimes de ódio, o resultado é positivo. Isso significa que há mais crimes de ódio nos países do grupo B do que nos países do 
grupo A. No entanto, embora relativamente alta, a diferença entre as médias não chega a ter confiança estatística, ficando aqui apenas como uma nota de observação que faz sentido com os argumentos mais gerais deste artigo.

Finalmente, resta observar que os países do grupo B de fato possuem uma população imigrante consideravelmente maior do que os do grupo A. Ainda que a diferença das médias não seja estatisticamente significativa, pode ser considerada alta: $1,45 \%$.

\section{RESULTADOS E CONTRIBUIÇÃO}

Os resultados encontrados sugerem, em suma, que a atitude de suportar PEDs está mais fortemente relacionada à falta de confiança na UE e, consequentemente, à rejeição da ideia de uma Constituição europeia, bem como à percepção do eleitor de que ele é informado a respeito da UE, do que às frustrações ou à satisfação quanto aos benefícios econômicos que a integração europeia pode representar. Isso sugere que a defesa de valores, crenças e identidades se torna preponderante sobre as vantagens materiais que uma integração econômica é capaz de gerar.

Algumas diferenças de médias não apresentaram relevância estatística, como foi o caso das variáveis de representação. Estas especificamente merecem um tratamento mais acurado, o que provavelmente dependeria de uma investigação sobre a correlação das variáveis de representação e seus efeitos em uma série temporal capaz de agregar mais precisamente informação sobre o crescimento de votos em PEDs e as reformas que sofreram o Conselho de Ministros e o Parlamento Europeu na necessária redistribuição de cadeiras após cada um dos rounds de alargamento da UE.

Os resultados encontrados ajudam a compreender países como Grécia e Itália, que indubitavelmente se beneficiam da integração econômica ao mesmo tempo que suas sociedades suportam PEDs que se opõem à integração política. Por outro lado, países como o Reino Unido, que sempre foi marcado por sua posição histórica de resistência à integração, não possuem uma significativa tradição em suportar PEDs. Observe-se que o Reino Unido apresenta um índice baixíssimo - o mais baixo - de percepção social de informação sobre a UE (3,7\% da sociedade do Reino Unido considera saber um pouco sobre a UE) (Eurobarometer 64, 2005), como se a indiferença às políticas da UE pudessem pou- 
par os cidadãos britânicos das garras das instituições europeias. Essa conclusão só pode ser fruto da falta de informação a respeito de quanto as instituições britânicas atualmente já se encontram entrelaçadas com as europeias e de que a não adoção do euro, por exemplo, não é salvaguarda para a desobediência, por exemplo, das decisões da Corte de Justiça Europeia. Aquelas sociedades que mais percebem os efetivos poderes instituídos na nova instância europeia de competição e barganha política são as mesmas que têm demonstrado também ressentimento no que tange à homogeneização cultural e nacional em meio à integração econômica. Isso sugere que o eleitor que tem mais consciência sobre os poderes das instituições europeias e suas consequências pode também temê-las. A compreensão sobre o estabelecimento de uma instância supranacional de decisões políticas que interferem na autonomia dos poderes Executivo, Legislativo e Judiciário nacionais não parece gerar comportamentos indiferentes ao processo de integração social.

Os dados levantados contribuem para confirmar outros achados da literatura (Ignazi, 1996; 2003; Mudde, 2007; Kitschelt, 1995; Betz, 1994) segundo a qual a preferência pela intolerância não está fundamentada na percepção de que realmente há perdas de natureza material e econômica, por parte das sociedades europeias, em função da integração regional. $\mathrm{O}$ foco de preocupações e reivindicações da nova clivagem política é a identidade.

Enfim, a capacidade de interferência no processo decisório supranacional e a consciência dos limites dessa capacidade se tornam importantes variáveis para uma melhor compreensão do comportamento xenófobo na Europa. Essas conclusões estão em consonância com a mudança no perfil do eleitor da extrema-direita, que está se tornando mais jovem e com mais anos de educação, diferentemente do tradicional perfil associado a clivagens de classe.

\section{CONCLUSÕES}

Em 1900, a Europa reunia aproximadamente 20\% da população mundial. Hoje sua população representa $11 \%$, e as previsões são para que, em 2050, represente apenas $4 \%$ da população de todo o planeta. Parece evidente que, nos próximos anos, a região necessitará passar por uma nova onda migratória, e o Parlamento Europeu já se manifestou recentemente sobre a necessidade da imigração como um tópico importante 
na agenda sobre medidas de sustentação do poderio europeu ${ }^{11}$. Ou seja, do ponto de vista demográfico, a imigração é necessária para a Europa, além de a índole europeia sempre ter sido migratória. Assim como a migração interna naturalmente sempre foi facilitada pela condição geopolítica dos pequenos países europeus, ao mesmo tempo a xenofobia e a intolerância também são ingredientes antigos na região. O que há então de novo em todo o quadro apresentado neste artigo?

Se há alguma novidade quanto à atitude intolerante ou xenófoba em relação a situações de intolerância no passado da história europeia, ela está na forma de organização e de articulação de ideias não democráticas. O voto na nova extrema-direita vem sendo também largamente interpretado como um voto de protesto do eleitor que está desacreditado e desconfiado dos políticos locais e nacionais, e que, naturalmente, não apoiaria a criação de mais instâncias políticas representativas ou decisórias - como as instituições europeias. Assim, o inusitado é que o resultado vem sendo o fortalecimento de partidos políticos que disputam eleições dentro das regras do jogo democrático para ganhar legitimidade para a defesa da implementação de agendas que visam restringir o mesmo jogo democrático do qual eles vêm se beneficiando no último quarto de século.

(Recebido para publicação em setembro de 2008)

(Versão definitiva em janeiro de 2009) 


\section{NOTAS}

1. Foram pesquisados os sites oficiais dos Parlamentos nacionais de cada país, além de outros, como http: / www.electionworld.org; http:/ / www.electoralgeography. com/new/en/elections; http://www.electionresources.org; http:/ / www. electionguide.org/index.php (acessados em 10/10/2008).

2. Os dados das eleições e os votos recebidos por partido político são disponibilizados pelos órgãos oficiais de cada Parlamento nacional. Não há uma fonte única, assim, para este artigo, foram consultados individualmente os dados por eleição e os votos por partido em cada país.

3. Espanha e França possuem uma população de imigrantes similar (em torno de 5,5\%), no entanto, na Espanha não há tradição de suporte a partidos políticos xenófobos como há na França.

4. Nos anos em que não houve eleição nacional, foram repetidos os percentuais da última eleição para efeito da contagem ano a ano, considerando-se que as eleições nacionais nos países pesquisados não são realizadas nos mesmos anos. Esse foi um artifício encontrado para considerar os intervalos eleitorais diferenciados, bem como, em alguns casos, os termos dos mandatos.

5. Os gráficos foram construídos a partir dos resultados da pesquisa sobre os percentuais de votos por eleição nacional em cada país e por partido político de extrema-direita consultados nos sites oficiais dos Parlamentos nacionais dos países estudados e em http://www.electionworld.org (os resultados estão resumidamente organizados em tabela apresentada no Apêndice).

6. O critério para apuração das médias de votos atribuídos em cada país ao longo do período pesquisado foi o mesmo usado para o Gráfico 1, qual seja, a repetição dos percentuais nos anos de intervalo das eleições.

7. Os dados usados para a medição das variáveis contra a Constituição Europeia e falta de confiança na UE foram retirados do Eurobarometer 63 (2005); para informação sobre as instituições europeias, do Eurobarometer 64 (2005).

8. Disponível em http://www.emz-berlin.de (acessado em 8/10/2008).

9. Trata-se de um teste $Z$ cuja fórmula utilizada é a seguinte: $Z=\left(X_{1}-X_{2}\right)-\left(\mu_{1}-\mu_{2}\right) / \sigma_{x 1}$ $\mathrm{x}_{2}$.

10. Isso porque os partidos radicais de esquerda, ao contrário dos partidos radicais de direita, vêm perdendo votos progressivamente na Europa ocidental.

11. Naturalmente, isso não significa que haverá facilitação para o blue-collar worker, pois interessa a esses países uma imigração regulada, e as mudanças nas políticas regionais demonstram que a seleção dessa imigração tem sido cada vez mais acurada. 


\section{REFERÊNCIAS BIBLIOGRÁFICAS}

BETZ, Hans-Georg. (1994), Radical Right-Wing Populism in Western Europe. New York, St. Martin's Press.

DE MASTER, Sara e ROY, Michael Le. (2000), "Xenophobia and the European Union". Comparative Politics, vol. 32, no 4, pp. 419-436.

IGNAZI, Piero. (1996), “The Intellectual Basis of Right-Wing Anti-Partytism”. European Journal of Political Research, vol. 29, no 3, pp. 279-296.

. (2003), Extreme Right Parties in Western Europe. Oxford, Oxford University Press.

KITSCHELT, Herbert. (1988), “Left-Libertarian Parties: Explaining Innovation in Competitive Party". World Politics, vol. 40, no 2, pp. 194-234.

. (1994), The Transformation of European Social Democracy. New York, Cambridge University Press.

. (1995), The Radical Right in Western Europe: A Comparative Analysis. Michigan, University of Michigan Press.

MARKS, Gary, WILSON, Carole e RAY, Leonard. (2002), "National Political Parties and European Integration". American Journal of Political Science, vol. 46, no3, pp. 585-594.

MARKS, Gary et alii. (2006), "Party Competition and European Integration in East and West. Different Structure, Same Causality". Comparative Political Studies, vol. 39, no 2, pp. 155-175.

MUDDE, Cas. (1996), "The War of Words Defining the Extreme Right Party Family". West European Politics, vol. 19, no 2, pp. 225-248.

. (2007), Populist Radical Right Parties in Europe. New York, Cambridge University Press.

POGUNTKE, Thomas e SCARROW, Susan. (1996), “The Politics of Anti-Party Sentiment: Introduction". European Journal of Political Research, vol. 29, oㅡ 3, pp. 257-262.

TAGGART, Paul. (1998), “A Touchstone of Dissent: Euroscepticism in Contemporary Western European Party Systems". European Journal of Political Research, vol. 33, no 3, pp. 363-388.

VAN DIJK, Jan et alii. (2005), "The Burden of Crime in the EU Research Report". A Comparative Analysis of the European Survey of Crime and Safety. European Crime and Safety Survey, EU ICS.

VEUGELERS, John e CHIARINI, Roberto. (2002), “The Far Right in France and Italy: Nativist Politics and Anti-Facism", in M. Schain, A. Zolberg e P. Hossay (eds.), Shadows over Europe: The Development and Impact of the Extreme Right in Western Europe. New York, Palgrave, pp. 83-103.

VEUGELERS, John e MAGNAN, André. (2005), “Conditions of Far-Right Strength in Contemporary Western Europe: An Application of Kitschelt's Theory". European Journal of Political Research, vol. 44, no 6, pp. 837-860. 


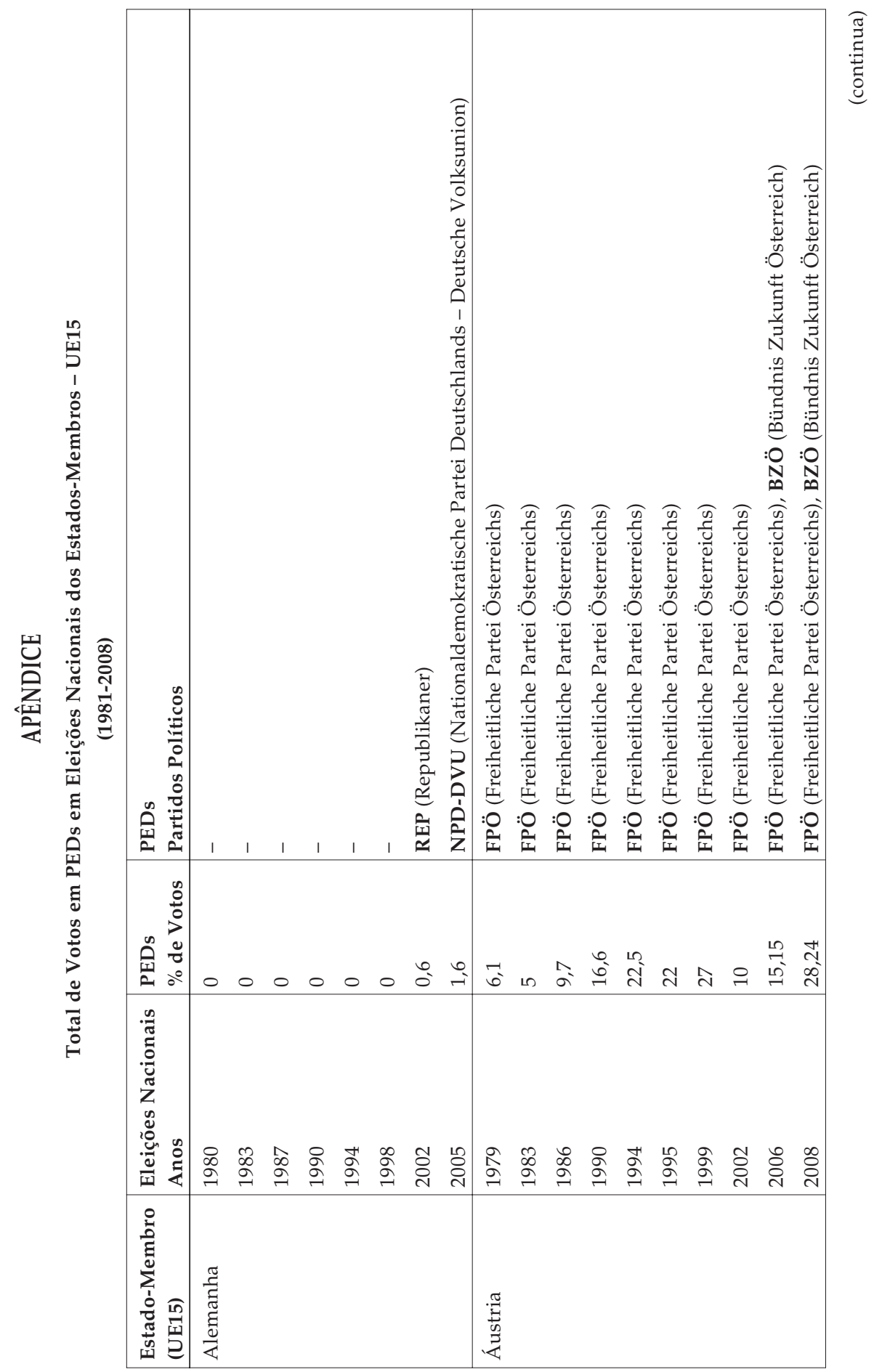


Razões da Intolerância na Europa Integrada

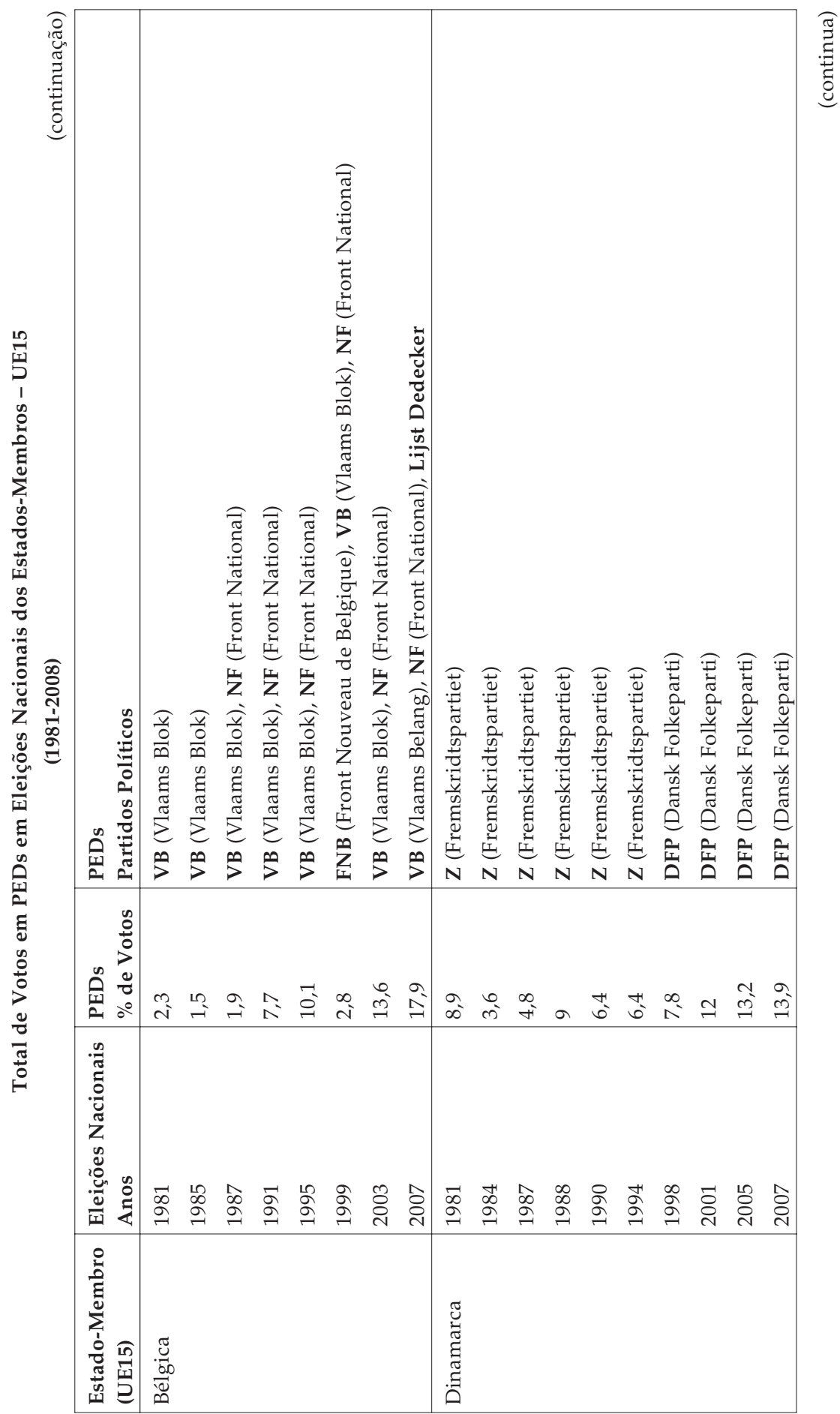


Ana Paula Tostes

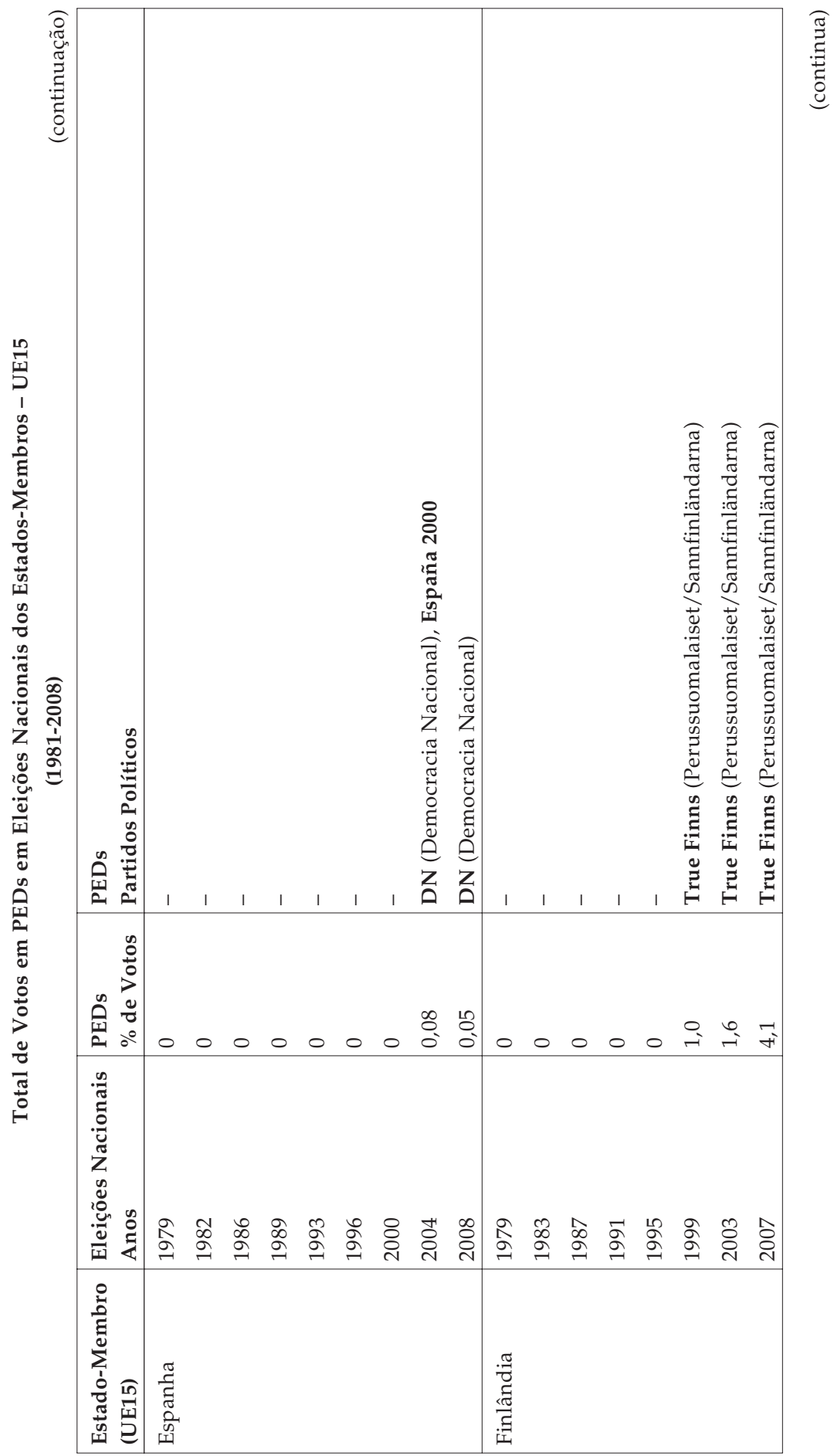


Razões da Intolerância na Europa Integrada

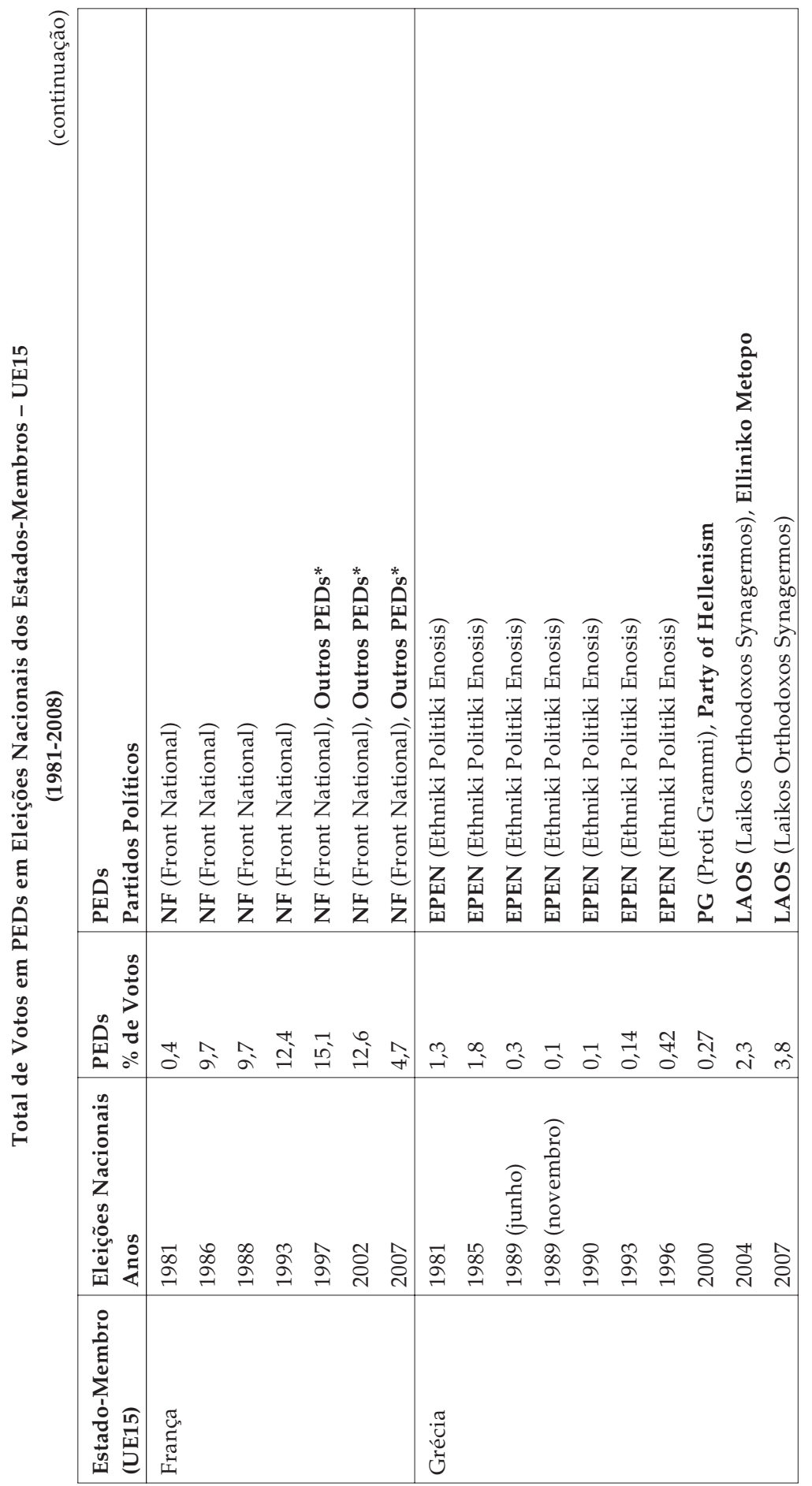


Ana Paula Tostes

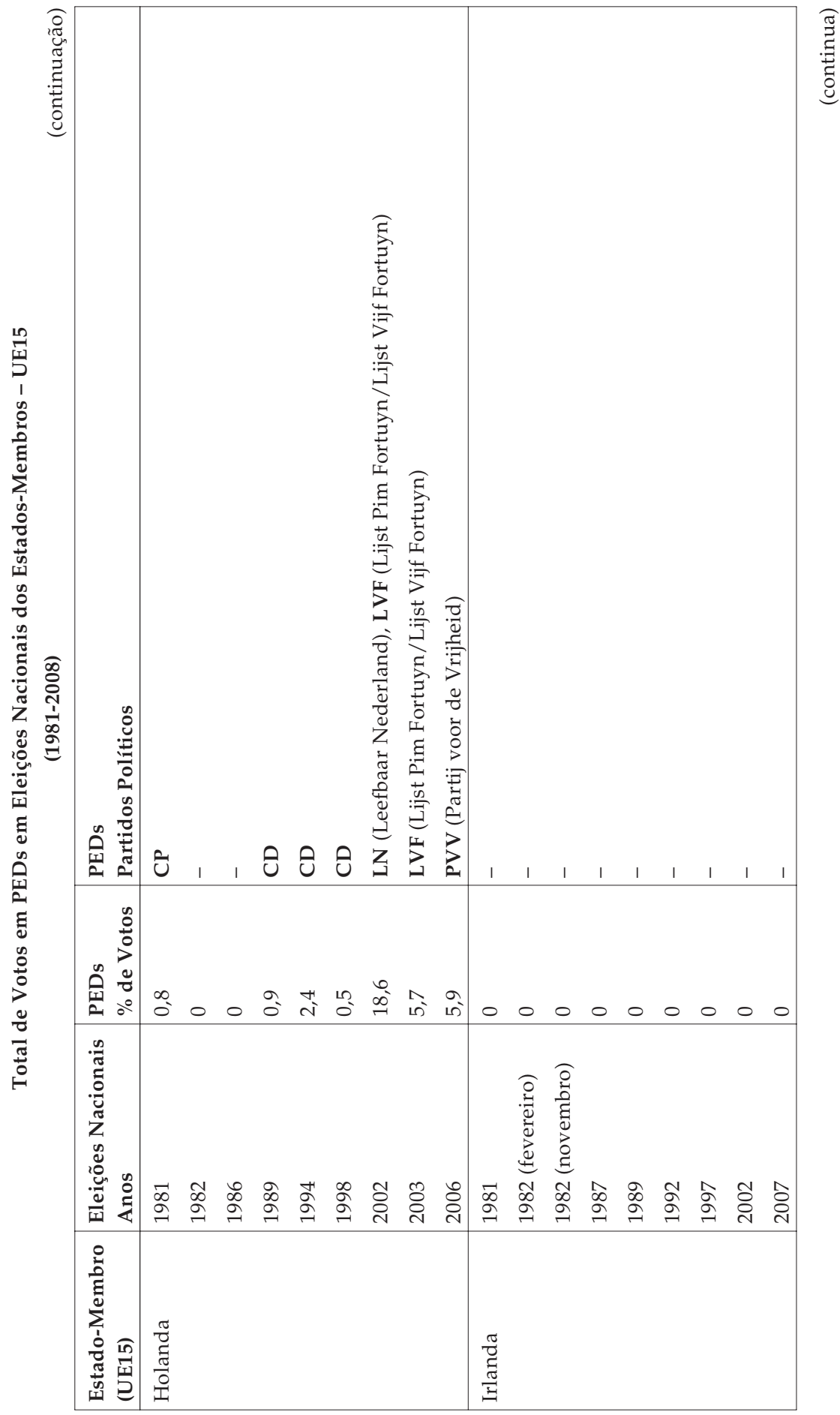


Razões da Intolerância na Europa Integrada

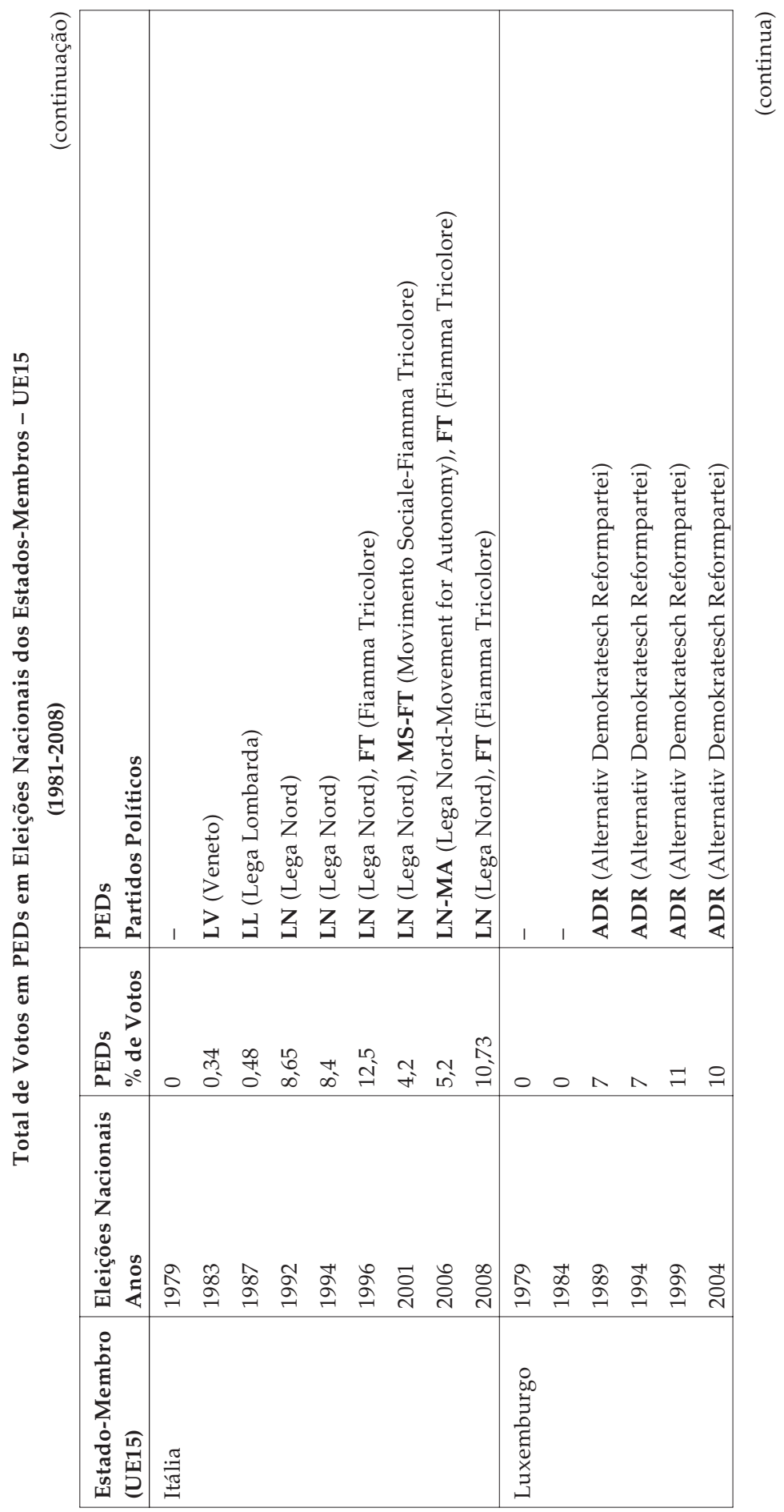


Ana Paula Tostes

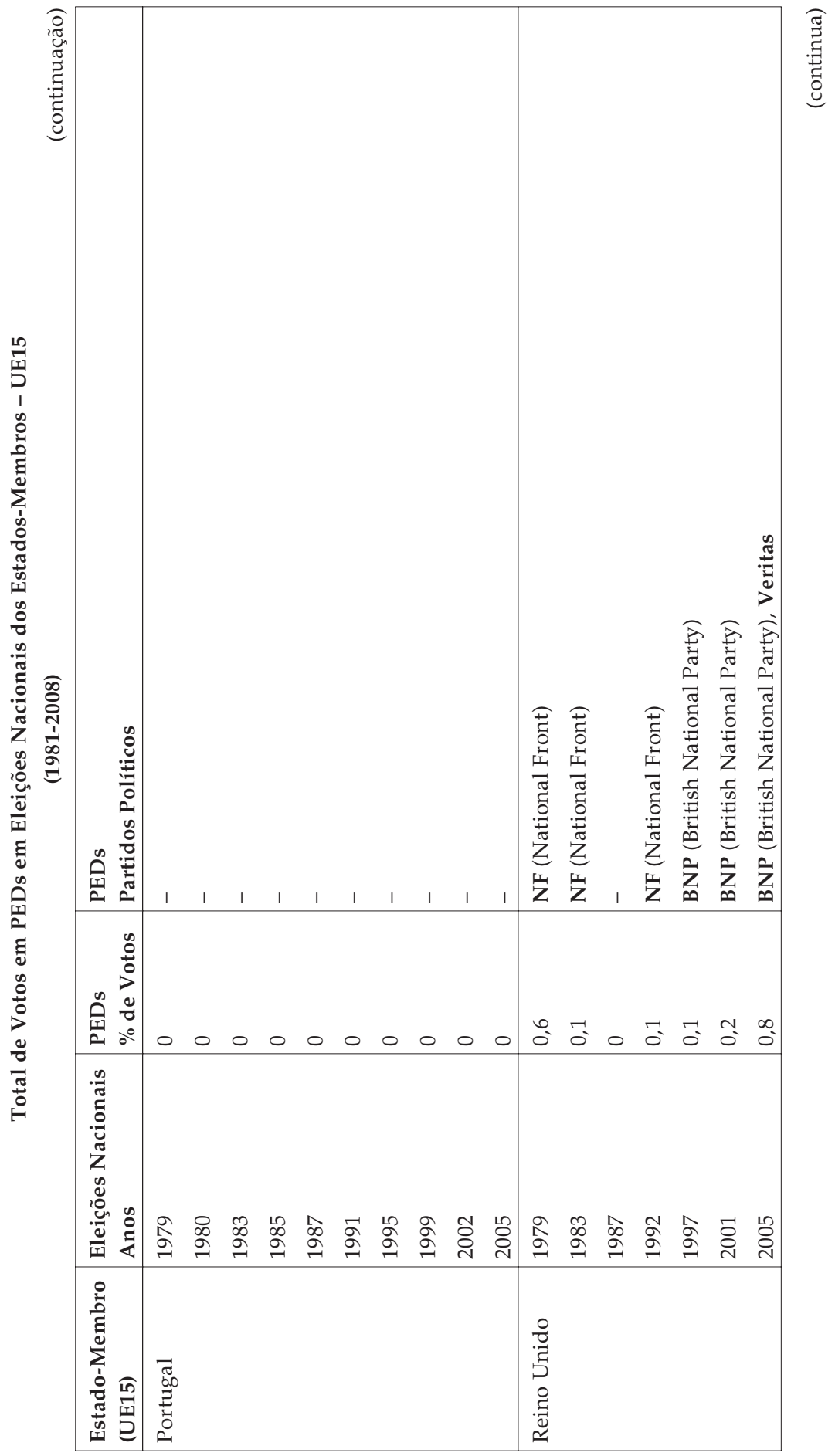


Razões da Intolerância na Europa Integrada

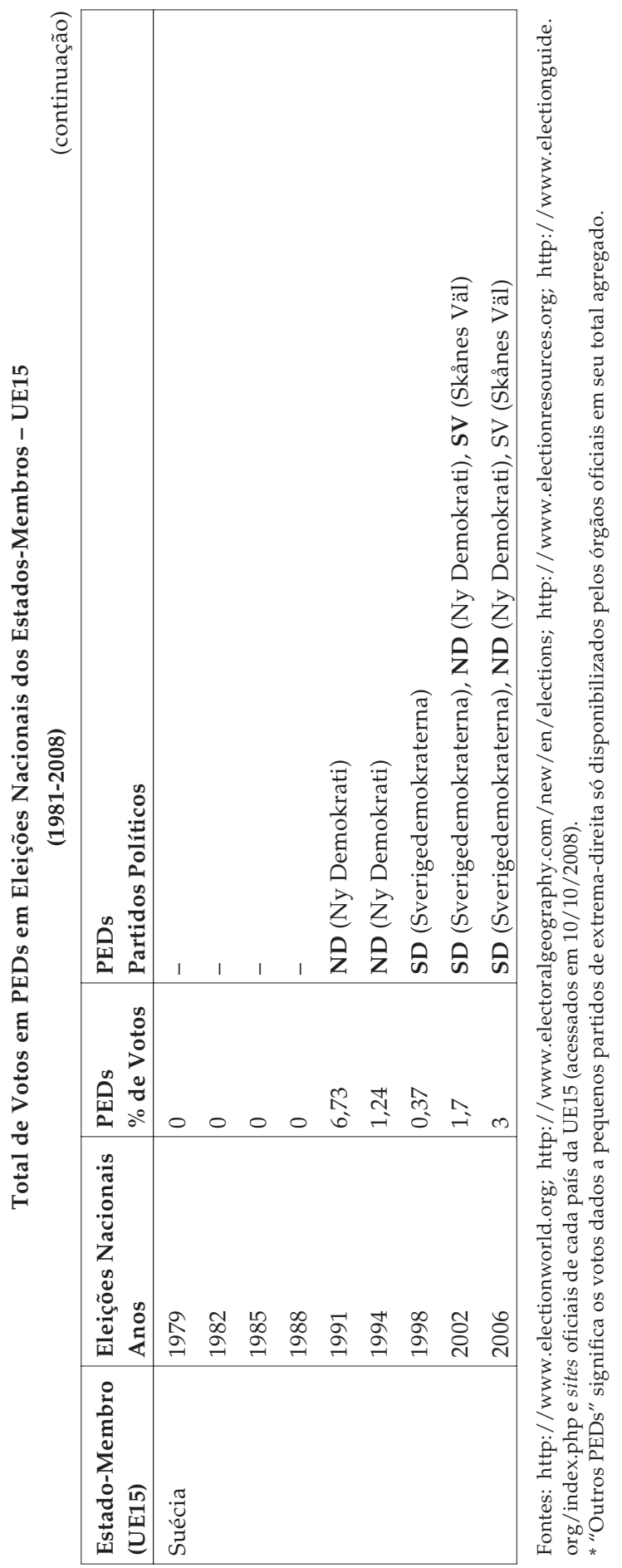




\section{ABSTRACT \\ Reasons for Intolerance in Integrated Europe}

The article contends that Euroscepticism is a fundamental variable for a good understanding of the support for new extreme right-wing party platforms in national elections among all Western European countries. Based on voting data for parties aligned with the new far right in European national elections, the article maps the growth of extreme right parties and tests the correlation between the support for intolerance and variables pertaining to economic and social issues, perception, and representation. The findings provide empirical evidence to confirm that the preference for intolerance is not based on material or economic dissatisfaction, since identity is the main focus of concerns and claims in the new political cleavage that supports the new extreme right.

Key words: European Union; extreme right; Euroscepticism; European national elections

\section{RÉSUMÉ}

Raisons de l'Intolérance dans l'Europe Intégrée

Dans cet article, on affirme que l'attitude euro-sceptique est une variable fondamentale pour la réflexion sur la préférence que les électeurs européens occidentaux montrent envers des programmes de partis d'extrême droite lors de leurs élections nationales. À partir des données recueillies concernant les votes en faveur des partis qui suivent la nouvelle idéologie d'extrême droite lors des élections nationales européennes, on dresse la carte de la croissance des partis d'extrême droite sur ce continent et on pose la corrélation entre le soutien donné à l'intolérance, d'une part, et les variables économiques et sociales, de perception et de représentation, de l'autre. Les résultats viennent confirmer empiriquement que la préférence pour l'intolérance ne se fonde pas sur des insatisfactions de nature matérielle et économique, puisque la principale source d'inquiétude et de revendications issue du nouveau clivage politique sur lequel s'appuie la nouvelle extrême droite c'est l'identité.

Mots-clé: Union Européenne; extrême droite; euro-scepticisme; élections nationales européennes 